\title{
Who Uses Electronic Banking? Results from the 1995 Survey of Consumer Finances
}

\author{
Arthur B. Kennickell*
}

Myron L. Kwast*

Prepared for presentation at the Annual Meetings of the Western Economic Association

Seattle, Washington

July 1997

* Division of Research and Statistics, Board of Governors of the Federal Reserve System, Washington, DC 20551. The views expressed are those of the authors and do not necessarily reflect those of the Board of Governors or its staff. We wish to thank Edward Ettin, Diana Hancock, Heidi Richards, Pat Rudolph, and Martha Starr-McCluer for comments on an earlier draft. All errors remain the sole property of the authors. Kevin Moore provided outstanding research assistance. 


\section{Who Uses Electronic Banking? \\ Results From the 1995 Survey of Consumer Finances}

\section{Introduction}

Households' use of electronic media for making financial transactions and decisions, including the use of more narrowly defined "electronic money," has received ever increasing attention in a wide variety of forums, including the financial community, the government, academia, and the press. The role of the Internet in changing the means by which households obtain financial information has also been much discussed.

Much of the discussion of electronic banking has focused on the supply side of the market. Frequently discussed issues include: How and what types of electronic products are being provided by banks and other producers of financial services? How will electronic banking affect the competitive position of banks and other financial institutions? For example, will Internet banking "commoditize" financial services to the point that any existing locational rents are made irrelevant? Much of the rest of the discussion has revolved around potential public policy concerns, such as consumer protection and privacy, deposit insurance, money laundering and other law enforcement issues, and monetary policy. ${ }^{1}$ Relatively little of the discussion to date has addresssed the demand side of the market, or such questions as: What types of products are consumers likely to be actually willing to pay for? What are the characteristics of current and likely future purchasers of electronic products and services? How quickly will consumers adopt electronic technologies?

Clearly, knowledge of actual and potential demand is critical for assessing the likelihood of most scenarios regarding the impacts of electronic banking and other information technology. Thus, the relative neglect of demand side issues is a major gap in our ability to assess both the

\footnotetext{
${ }^{1}$ For an excellent review of what we know about, and issues raised by, electronic banking, see the Congressional Budget Office (1996). For a discussion of policy issues see Blinder (1995). The "role of government" and other issues were discussed extensively at a recent conference sponsored by the U.S. Department of the Treasury (September 19-20, 1996). For information on the participation by banks in Internet banking in both the U.S. and Europe, see Booz-Allen and Hamilton (New York (July 1996), London (July 1996), and New York (February 1996)), and Grant Thornton (1996).
} 
present and the future ${ }^{2}$. This neglect is due in part, and perhaps even primarily, to the lack of data on the current and potential use of electronic products by households and other consumers. Part of this information gap is being filled by a number of experiments, such as the smart card pilot being conducted by several private firms since July 1995 in Swindon, England, and the U.S. trial of stored-value cards conducted at the Atlanta Olympics. Such experiments, while useful, run the risk of providing misleading results since they are conducted in what are, in many ways, quite limited environments. Another approach, and one that provides data generated by the free market, is to survey consumers' actual usage of electronic media, and to examine key characteristics of both those who do and those who do not use such products and services.

This paper reports results of one of the first, and to our knowledge the most comprehensive, attempts to implement the strategy of surveying current users of electronic services. The study analyzes data from the 1995 Survey of Consumer Finances (SCF), which included a battery of questions regarding households' use of electronic media for financial transactions and decision making. Since the SCF also collects a large amount of other data on respondents' assets, liabilities, income, expenses, use of financial services, and demographic characteristics, the survey provides an extremely rich source of information on not only the current usage of electronic media, but also the socio-economic characteristics of both users and nonusers. Indeed, we believe the 1995 SCF provides the best opportunity available to establish "benchmark" statistics on households' use of electronic media for financial transactions and decision making.

The next section presents a brief review of the burgeoning electronic banking "literature," with a focus on demand-side concerns, and provides some aggregate perspective on the use of electronic payments instruments. Section III summarizes the $1995 \mathrm{SCF}$, and gives the definitions of electronic products and services used in this study. Section IV contains our analysis of the survey data, and the final Section gives our conclusions. Additional data are provided in the Appendix.

\footnotetext{
${ }^{2}$ An interesting and important current example is the upcoming January 1, 1999 deadline for mandatory electronic transfer of virtually all Federal cash payments.
} 


\section{Literature Review and Background}

When considering the role of electronic media in financial transactions and decision making, it is useful to begin with an overall perspective on the mix of electronic payments and other types of payments technologies. Unfortunately, the data to make such comparisons for either the economy as a whole or the household sector alone are incomplete, at best. Probably the best source for such comparisons are data constructed by the Bank for International Settlements (BIS) on the use of various cashless payments instruments. Table 1 provides BIS estimates for the United States of both the number and the dollar value of transactions, where the payments instruments shown are limited to small dollar instruments used typically by households. ${ }^{3}$

Several aspects of the data in table 1 are noteworthy. First, using either the number or the dollar value of transactions as the criterion, checks dominate the small dollar noncash payments system. However, throughout the first half of the 1990s checks' relative importance declined steadily, albeit only modestly, from 82 percent of the number of transactions ( 93 percent of the dollar value) in 1990 to 78 percent of the number (89 percent of the value) in 1994. Second, at least in terms of the number of transactions, credit cards are by far the second most important small dollar payments technology. However, in dollar terms, the Federal Reserve's Automated

Clearing House (ACH) comes in a clear second to checks. ${ }^{4}$ Finally, while the relative importance of checks declined, the relative importance of electronic payments obviously increased. Thus, these aggregate data are consistent with a growing willingness by households to use electronic payments technologies. Indeed, the average annual growth rates for the electronic technologies are impressive. ${ }^{5}$

\footnotetext{
${ }^{3}$ However, as the footnotes to the table indicate, commercial and government transactions are included in the data. Large dollar instruments, such as Fedwire transfers, are excluded.

${ }^{4}$ This is probably because ACH debits and credits are relatively large (small) dollar transactions, such as payroll, pension, and mortgage payments.

${ }^{5}$ Average annual growth rates for the number (dollar amount) of debit card, credit card, ACH credits, and $\mathrm{ACH}$ debits are 69 percent (58 percent), 8 percent (14 percent), 16 percent (33 percent), and 19 percent (14 percent).
} 
Table 1

Indicators of Use of Various Cashless Payment Instruments

Number of Transactions (millions)

Value of Transactions (\$billions)

United States

\begin{tabular}{|c|c|c|c|c|c|}
\hline Instruments & 1990 & 1991 & 1992 & 1993 & 1994 \\
\hline Checks issued $^{1} \ldots .$. & $55,400.0$ & $57,470.0$ & $58,400.0$ & $60,297.2$ & $61,670.0$ \\
\hline Value................................. & $\$ 70,000.0$ & $66,000.0$ & $67,000.0$ & $69,160.7$ & $71,500.0$ \\
\hline \multicolumn{6}{|l|}{ Payments by card: } \\
\hline Debit $^{2} \ldots \ldots \ldots \ldots$ & 278.0 & 301.0 & 505.0 & 672.0 & $1,046.0$ \\
\hline Value........ & $\$ 13.5$ & 16.3 & 21.8 & 28.9 & 44.9 \\
\hline Credit $^{3}$. & $10,478.1$ & $11,241.0$ & $11,700.0$ & $12,516.0$ & $13,681.6$ \\
\hline Value......... & $\$ 465.8$ & 485.0 & 529.1 & 620.6 & 730.8 \\
\hline \multicolumn{6}{|l|}{ Paperless credit transfers: } \\
\hline Federal Reserve $\mathrm{ACH}^{4}$. & 940.8 & $1,058.6$ & $1,189.5$ & $1,345.8$ & $1,525.7$ \\
\hline Value................................... & $\$ 1,423.8$ & $2,462.7$ & $2,411.7$ & $2,698.9$ & $3,284.8$ \\
\hline \multicolumn{6}{|l|}{ Direct debits: } \\
\hline Federal Reserve $\mathrm{ACH}^{5} \ldots \ldots$. & 486.6 & 572.6 & 653.8 & 739.3 & 847.0 \\
\hline 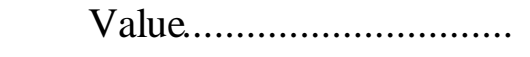 & $\$ 3,236.7$ & $3,809.9$ & $4,978.8$ & $4,896.3$ & $5,084.7$ \\
\hline Total........................................ & $67,583.5$ & $70,643.3$ & $72,448.3$ & $75,570.3$ & $78,770.3$ \\
\hline Value................................. & $\$ 75,139.8$ & $72,773.9$ & $74,941.4$ & $77,405.4$ & $80,645.2$ \\
\hline
\end{tabular}

1. Includes personal checks, commercial and government checks, commercial and postal money orders and travellers' checks. Data for the volume of checks not processed by the Federal Reserve are estimated.

2. Estimates are based on June data and include on-line POS debits and ACH/POS debits. Source: POS News (Faulkner \& Gray, New York).

3. Includes all types of credit card transactions (i.e., bank, oil company, telephone, retail store, travel and entertainment, etc.). Bank cards include VISA and MasterCard credit cards only (excluding debit cards). Source: The Nilson Report (Oxnard, CA).

4. Does not include commercial "on-us" ACH credit transactions originated and received by the same bank. NACHA estimates that "on-us" items increase total ACH volume (debits + credits) by about 24 percent in 1994. 5. Does not include commercial "on-use" debit items. Volume data exclude debit items with no value such as notifications of changes in customer information.

SOURCE: BIS (1995) 
Two recent studies have attempted to examine actual and potential household demand for electronic, but not necessarily banking, products. CommerceNet (an Internet industry association) and Nielsen Media Research surveyed around 4200 persons aged 16 and older in the United States and Canada in August 1995, and then re-interviewed about 2800 respondents in March/April 1996. The main purpose of the survey was to examine use of the Internet, and particularly the World Wide Web (WWW). Unfortunately, results across the two surveys are somewhat difficult to interpret, since the definition of an Internet "user" was broadened in the reinterview. Nevertheless, the results are probably fairly suggestive of Internet use.

Key findings of the CommerceNet/Nielsen survey relevant to our current study include: (1) access to the Internet among respondents grew by 50 percent between August 1995 and March 1996, when some 24 percent of households were estimated to have access to the Internet; (2) use of the Internet and WWW appeared to have grown substantially; (3) new users, while still "upscale," encompassed a broader spectrum of the population; for example, compared to "longtime users," smaller percentages of new users owned a home computer ( 72 percent compared to 88 percent), had a college degree (39 percent compared to 56 percent), and lived in households with annual incomes of at least $\$ 80,000$ (17 percent compared to 27 percent), (4) commercial uses of the Internet, the buying and selling of products and services, were growth areas, and (5) substantial proportions of respondents who said they had access to (21 percent) or used (11 percent) the Internet in August 1995 did not have access in March 1996; major reasons for losing access included no need, canceled Online service, too expensive, and changed job. Overall, these results, while not aimed directly at electronic banking, suggest a growing willingness and ability among an increasingly broad (although still fairly narrow) range of households to use electronic media for commercial purposes. However, they also suggest that many users have tried the Internet, and found it wanting at its current state of development.

A study by the consulting firm Booz-Allen and Hamilton (BAH, 1996) was targeted on consumer demand for Internet, or WWW, banking. Using a variety of outside studies and their own proprietary models, the BAH study predicted that the use of Internet banking would grow rapidly from only 0.1 percent of U.S. households at the end of 1996 to 15.7 percent of U.S. households, or a little over 16 million users, by the end of 2000. Key inputs to this forecast were 
projections of the proportion of banks offering Internet banking, household computer and modem penetration rates, overall Internet usage, and the demographic characteristics of users. With regard to demographics, the study assumed that "younger consumers are more likely to use online banking today," but " as these people age they will raise the likelihood of usage in older segments." ${ }^{6}$ While the study projected rapid growth in Internet banking, it also argued that many households that use the Internet as their primary banking device "will continue to use other channels such as the phone and the branch."7

These results, plus others that seem to appear almost daily, clearly reinforce the view that the use of electronic banking products, and electronic media in general, are increasingly important aspects of American life. In particular, a strong case can be made that understanding the present and potential future of electronic technology in banking is critical to understanding current and future trends in the financial services industry. But even the present state of affairs is unclear, and the future of electronic banking is, indeed, controversial. The rest of this paper attempts to establish a range of important baseline facts regarding the state of electronic banking among American households.

\section{The 1995 Survey of Consumer Finances}

Beginning in 1983, the Survey of Consumer Finances (SCF) has been conducted every three years by the Federal Reserve Board in cooperation with the Statistics of Income Division of the Internal Revenue Service. Interviewing for the 1995 SCF, which is used in this paper, was performed by the National Opinion Research Center at the University of Chicago between the months of June and December of 1995. The survey over-samples wealthy households to provide a larger basis for estimates of narrowly-held assets, but the survey also provides weights to adjust each household to an estimate of its proper representation in the set of all of U.S. households (Kennickell and Woodburn [1997]). A total of 4,299 households were interviewed in $1995 .^{8}$

\footnotetext{
${ }^{6}$ Booz-Allen and Hamilton (1996), p. III-11.

7 Idem.

${ }^{8}$ The data available on the Internet at http://www.bog.frb.fed.us/pubs/oss/oss2/scfindex.html.
} 
Although the SCF is well-known as the best source of household-level balance sheet information for the full population, it is less well-known that the survey contains substantial information on the use of financial services. In response to the growing interest in electronic banking, several new questions were added to the 1995 survey and several existing questions were modified to provide information on this subject. The results in this paper derive principally from three sequences of questions.

First, for each financial institution (up to a maximum of six) that a given household uses, the survey asks how the respondent's family mainly deals with the institution. ${ }^{9}$ Respondents could report up to eight types of technology they use to access each institution, and interviewers were trained to probe for additional responses. Second, respondents were asked a series of questions about specific electronic instruments. These included a question each on debit cards and smart cards, and a pair of questions about the use of automatic deposit and pre-authorized debits followed by specific questions on the types of automatic deposits or withdrawals. ${ }^{10}$ It is worth noting that the emphasis in the questions on automatic deposit and withdrawal and debit cards was on using these services, whereas the question about smart cards focused on having such a card. Finally, a pair of questions asked respondents about the types of information they use in saving and borrowing decisions. ${ }^{11}$

\footnotetext{
${ }^{9}$ The exact question text is "How does your family mainly do business with this institution — by cash machine, in person, by mail, by phone, by computer, or in some other way?" "Family" was defined for the respondent to include only people living in the household. The "other" responses were recorded verbatim and coded after the interview.

${ }^{10}$ The survey asks the following four questions: (1) "A debit card is a card that you can present when you buy things that automatically deducts the amount of the purchase from the money in an account that you have. Does your family use any debit cards?" (2) "A 'smart card' is a type of payment card containing a computer chip which is set to hold a sum of money. As the card is used, purchases are subtracted from that sum. Do you or anyone in your family living here have any such cards that you can use for a variety of purchases?" (3) "Some people have their paychecks or Social Security benefits or other money automatically paid directly into their accounts. Do you have any money directly deposited into one of your accounts?" If yes, "What kinds of deposits are these?" (4) "Some people have their utility bills, mortgage or rent payments, or other payments automatically paid directly from their accounts without having to write a check. Do you have any payments that you make in this way?" If yes, "What sorts of payments are these?"

${ }^{11}$ Two questions were asked: (1) How do you and your spouse/partner make decisions about saving and investments? Do you call around for rates? Do you read newspapers, magazines, or material you get in the mail? Do you get advice from a friend, relative, lawyer, accountant, or financial planner? Or do you do something else?" (2) "What sorts of information do your and your spouse/partner use to make decisions about credit or borrowing? Do you call around for terms? Do you read newspapers, magazines, or material that you get in the mail? Do you
} 
Table 2: Percent of households using various types of technology to conduct business with financial institutions; for households with at least one financial institution. 1995 SCF.

Technology

1. In person

2. Mail

3. Phone

4. Electronic transfer

5. ATM

6. Debit card

7. Payroll deduction/

Direct deposit

8. Direct deposit

9. Paycheck

10. Social Security

11. Other

12. Pre-auth. debit

13. Utilities

14. Mort./Rent

$15 . \quad$ Other

16. Computer

\section{Memo items:}

17. One use

18. Two uses

19. Three uses

20. >= four uses

21. Any electronic use (lines 3, 4, 7, 16)
$\%$ of $\mathrm{HHs}$

86.7

57.4

26.0

17.6

34.4

19.6

59.6

50.7

29.4

18.7

11.6

23.6

4.8

6.5

16.2

3.7

25.0

35.7

68.6
IV. Household Use of Electronic Banking

This section uses data from the 1995 SCF to consider two issues: (1) types of technologies used to transact at financial institutions and (2) information sources, including types of electronic media, used to make saving and borrowing decisions.

\section{A. Technologies Used At Financial}

$\underline{\text { Institutions }}$

Table 2 gives the percentages of households using various types of technologies in 1995 to conduct business with their financial institutions. Memo items provide further detail. ${ }^{12}$ The portion of the population analyzed here and in the rest of this paper is U.S. households that use at least one financial institution (both depositories and nondepositories) either for depository or borrowing services - 92 percent of all households. Credit cards are

excluded from this analysis. Credit cards have been studied extensively elsewhere, raise complex

get advice from a friend, relative, lawyer, accountant, or financial planner? Or do you do something else?" Respondents could give multiple responses to each of these questions. The "something else" responses were recorded verbatim and coded after the interview.

${ }^{12}$ These data are also displayed in Figures 1 and 2. 
issues of the interrelationship between the execution of payment transactions and access to credit, and thus would greatly complicate our analysis. ${ }^{13}$

According to the survey data, personal visits (row 1) were used by an estimated 86.7 percent of households, and thus were by far the most common technology used. However, an electronic technology - payroll deduction/direct deposit — came in second, followed closely by the mail. Other technologies were much further down the list. ATMs were used by 34.4 percent of households, and phones - a mixture of technologies such as touchtone transfers and direct personal service at a bank or brokerage - by 26.0 percent. ${ }^{14}$ Debit cards, which in many cases are also ATM cards, were used by 19.6 percent of households. More purely electronic means electronic transfers (e.g., wire transfers and other occasional transactions) and the computer were used by distinctly smaller proportions of the population. Still, some form of electronic technology (row 21) was used by 68.6 percent of households. ${ }^{15}$

The survey provides more detailed information on direct deposits and pre-authorized debits. Just over half of all households with accounts use direct deposit, and a bit under a quarter use pre-authorized debits. Direct deposit use is dominated by paychecks and Social Security checks. ${ }^{16}$ The purposes for pre-authorized debits appear to be somewhat broader than for direct deposits. The single largest use of pre-authorized debits is "other," which includes mainly payments for insurance. ${ }^{17}$

As a descriptive device, we have disaggregated the use of these technologies by income, financial assets, age, and education. Each of these classifications seem likely to vary importantly across uses. Indeed, previous research and widespread speculation within the press and the

\footnotetext{
${ }^{13}$ For more information from the 1995 SCF on credit card use, see Kennickell, Starr-McCluer, and Sundén (1997).

${ }^{14}$ Interestingly, while 67 percent of households report they have an ATM card, only 34 percent report that they use it regularly.

${ }^{15}$ Note that our definition of electronic technologies excludes ATM and debit cards on the view that in 1995 ATMs were essentially cash machines, and that debit cards (a more electronic technology) could not be meaningfully separated from ATM cards for many analytic purposes. As ATMs become "smarter," this view may need to be changed. Data on ATMs and debit cards are displayed separately.

${ }^{16}$ The automatic deposits in the "other" category consist principally of pension and disability payments other than Social Security and investment income.

${ }^{17}$ Other significant components of this category are payments on loans other than mortgages, health club membership fees, and transfers to other accounts or investments.
} 
industry have suggested that the use of electronics is positively associated with income and education, and negatively correlated with age. If income is a reasonable proxy for households' sense of the value of their time, one might expect higher-income households to use technologies that offer flexibility and time saving features. Younger households and those with higher levels of education may be more likely to be early users of newer technologies. We have also included financial assets in our analysis under the assumption that households with higher levels of such assets, and thus more such assets to manage, should be more likely to use a variety of technologies and to seek out those that would reduce their efforts. ${ }^{18}$

For ease of interpretation, the disaggregated data are displayed graphically in Figures 3 through 10. ${ }^{19}$ Looking first at Figure 3, it appears that users of electronic technologies, ATMs, debit cards and the mail generally have substantially higher median incomes than do nonusers of each technology. The figure suggests little difference in the incomes of users and nonusers of in person services. The importance of income is reinforced in Figure 4, which shows that the median income of households that use four or more types of services is some 2.6 times the median income of households that use only one service. Turning to Figure 5, the level of a household's financial assets may be an even clearer discriminator between households that use electronic technologies and those that do not. The gaps in financial asset holdings between users and nonusers of any given electronic technology are generally quite wide compared to the gaps for nonelectronic technologies. The difference in the median financial assets of users and nonusers of the telephone is particularly striking. In addition, households that use four or more types of services have median asset holdings that are in impressive 16.8 times larger than those of households that use only one service (Figure 6).

Figure 7 displays median differences in the age of users and nonusers of various technologies. The influence of age appears mixed. The older median age of users of direct credits and debits reflects extensive use of electronic programs for receipt of Social Security

\footnotetext{
${ }^{18}$ Other research has suggested that financial assets and income can have independent effects in explaining the financial behavior of households. See Kennickell, Kwast, and Starr-McCluer (1996). The authors are currently examining more complex structural models. table 1 .

${ }^{19}$ All figures appear after the "References." The data underlying Figures 3-10 appear in Appendix
} 
11

Table 3: Sign and significance of variables in probit estimates of use of various technologies

Technology

In person

Mail

Phone

Electronic transfer

ATM

Debit card

Automatic deposit/withdrawal

Direct deposit

Preauthorized debit

Computer

Smart card

Electronic

Call around

Newspapers, magazines, television, radio

Friend, relatives, colleagues

Material in mail, ads

Financial planner, accountant, broker

Banker

Electronic

Call around

Newspapers, magazines, television, radio

Friend, relatives, colleagues

Material in mail, ads

Financial planner, accountant, broker

Banker

Income Fin'l assets

Age

Education

Technologies used at financial institutions

\begin{tabular}{cccc}
\multicolumn{5}{c}{ Technologies used at financial institutions } \\
\hline- & + & 0 & 0 \\
+ & + & - & + \\
+ & + & 0 & + \\
0 & + & - & + \\
0 & + & - & + \\
0 & + & - & + \\
- & + & + & + \\
- & + & + & + \\
0 & + & - & + \\
0 & + & - & +
\end{tabular}

Use of smart cards

$\begin{array}{llll}0 & 0 & 0\end{array}$

Information used for saving/investment decisions

\begin{tabular}{llll}
\hline 0 & 0 & - & + \\
- & + & - & + \\
0 & + & 0 & + \\
+ & 0 & - & + \\
0 & + & - & + \\
+ & + & 0 & + \\
0 & 0 & 0 & 0
\end{tabular}

Information used for borrowing decisions

\begin{tabular}{llll}
\hline 0 & 0 & 0 & 0 \\
0 & + & - & + \\
& & - & + \\
0 & + & - & + \\
0 & - & - & + \\
0 & 0 & 0 & + \\
0 & + & + & -
\end{tabular}

+ indicates that the coefficient was positive and significant at the $1 \%$ level.

- indicates that the coefficient was negative and significant at the $1 \%$ level.

0 indicates that the coefficient was not significantly different from zero at the $1 \%$ level. 
payments. Interestingly, the median age of phone users and nonusers is the same, perhaps reflecting the fact that telephones are a well-established electronic technology familiar to virtually everyone. Users of ATM cards are notably younger than nonusers. The median age of users of four or more types of services is six years less than that of households that use only one service (Figure 8).

The role of education (Figure 9) seems stronger than that of the other variables. The median years of education of the household head is substantially higher among users of all forms of electronic technology, and extends even to use of the mail. Median education of users and nonusers is close only for in person usage.

Overall, the data suggest that the roles of income and age are somewhat ambiguous with respect to their correlation with the use of electronic technologies at financial institutions, but that electronic media use is positively correlated with the levels of a household's financial assets and education. To gauge the independent effects of these four variables on the use of each technology, we estimated a series of probit regressions, which are summarized in the top panel of table 3. The dependent variable in each probit is a binary variable indicating whether the household used a given technology, and the independent variables are the log of the household's annual income, the log of its total financial assets, and the logs of the age and years of education of the household's head. In the table, a plus sign indicates that the variable, using a 1 percent level of statistical significance, increases the probability of a household's using the technology, a zero shows no effect, and a minus sign says the variable lowers the probability of use. ${ }^{20}$ Our focus on the sign and significance of the variables reflects the descriptive nature of the work reported here.

The probit results confirm the impressions of the table and charts. Income has a mixed influence on the probability of electronic media use, but the influence of greater financial assets is uniformly positive. Indeed, higher financial assets are estimated to increase the probability, ceteris paribus, of using all of the technologies examined, perhaps reflecting a perceived need by such households to use multiple means to manage complex assets. Age has a somewhat mixed effect,

\footnotetext{
${ }^{20}$ None of the reported insignificant variables would be reclassified even if the significance level were increased to 10 percent.
} 
with older people estimated to be less likely to use the mail, electronic transfers, ATMs, debit cards, preauthorized debits, and the computer. Greater age increases the probability of using direct deposits, but has no effect on the probability of use of the phone or in person. Higher levels of education increase the probability of use of all the technologies save in person where there is no effect.

Figures 11-14 probe more deeply into the relationship between households' use of various technologies and the four variables examined here. ${ }^{21}$ To clarify the structure of these figures, we discuss Figure 11 in detail. The figure shows the income distribution of users of various financial services relative to the income distribution of all households with at least one account at a financial institution. For each service, four income groups are represented. Each bar shows the percent of service users who are in the corresponding income group divided by the percent of all households in that income group. For example, the left-most four bars are all very close to 1.0, indicating that the use of in person services by income groups is virtually the same as the income distribution of all account holders. In other words, no income group has a "market share" of in person use larger than its population share. ${ }^{22}$

Figure 11 suggests that households with annual incomes below $\$ 25,000$ tend to use electronic technology with a frequency considerably below their frequency in the population. Indeed, the same can be said for such "nonelectronic" technologies as the mail, ATMs and debit cards. The lower income households appear to be mainly in person users. The middle class households - the $\$ 25,000$ to $\$ 50,000$ group - have a market share for the technologies about equal to their population share. However, use of electronic media picks up and tends to be disproportionately common among households with incomes above $\$ 50,000$. The group with incomes of $\$ 100,000$ or more accounts for a particularly large relative share of phone users. In addition, the memo items in Appendix table 2a indicate that use of multiple technologies is relatively more concentrated among households with incomes over $\$ 50,000$. Indeed, the disproportionate tendency of the lowest income households to use only one technology is striking. However, it is important to note that although higher-income households are likely to be more

\footnotetext{
${ }^{21}$ The data underlying these charts are given in Appendix tables $2 \mathrm{a}$ and $2 \mathrm{~b}$.

${ }^{22}$ However, it may still be the case that some groups use in person services more frequently than others.
} 
intensive users of electronic services, data in Appendix table 2a indicate that the absolute majority of use of every type of technology is by households with incomes of less than $\$ 50,000$.

Figure 12 describes technology use according to selected ranges of holdings of financial assets. The patterns are similar to those for income. Households with less than $\$ 25,000$ in financial assets tend to be relatively less intensive users of electronic media than are higher asset households. As with income, the top financial assets group accounts for a strikingly disproportionate share of phone users. As shown in Appendix table 2a, the use of multiple technologies is considerably more common among households with financial assets exceeding $\$ 25,000$.

Relative use by various age groups is depicted in Figure 13. The willingness of people under the age of 35 to use ATMs, debit cards, and the computer is striking, as is the unwillingness of households with heads over 65 to use these technologies. Use of all of the other technologies generally does not appear to be particularly out of line with each group's share of the financial institution using population.

Figure 14 explores the role of education. The importance of a college education for electronic media use seems quite pronounced. Households with a college degree or better are the only group where the use of electronic media always exceeds their share of the population by a substantial margin. Indeed, the next group down, those with some college education, is the only other group where electronic media use is equal to or greater than its share of the financial institution using population. Interestingly, in person use is spread about evenly across the groups. The importance of education is reinforced in the memo items in Appendix table 2b, which show that the incidence of multiple technology use is very much heavier among households with at least a college degree.

\section{B. Smart Cards}

When the study began, we anticipated finding that only a negligible percent of households had a smart card. The objective had been to establish a baseline rate to use in future studies of this rapidly evolving technology. The fear had been that many households would misunderstand the survey question. The survey suggests that a surprisingly large 1.2 percent of households (Appendix table 1) had a smart card at the time of the interview. The patterns of use (higher 
income, financial assets, education, and younger age) suggest that households reporting smart cards are the ones most likely to have understood and answered the question correctly. However, in the probit regressions reported in table 3 , only the level of education has a significant (and positive) coefficient. In addition, external estimates indicate that less than 50,000 domestic smart cards were in use at the time of the survey. ${ }^{23}$ Although it is possible that some of the cards reported were obtained abroad, the survey estimate of ownership is almost certainly too high. Thus, the figure reported here should be taken as an upper bound on smart card ownership. C. Information Used For Saving and Borrowing Decisions

In addition to transactions services, households also consume services at financial institutions that reflect households' saving and borrowing decisions. Thus, the types and sources of information used by households to make these decisions are of obvious interest to providers of financial services. ${ }^{24}$ In recent years, the use of electronic media to provide financial information to households has become increasingly common, and some observers predict that electronic means

${ }^{23}$ Test marketing at that time included several college campuses, a football stadium in Florida, a ski resort, an electronic benefits program in Ohio, several bank in-house pilots, and some U.S. military installations.

${ }^{24}$ Not to mention to those who would understand the macroeconomics of saving, investment and borrowing. 
Table 4: Percent of households using various types of information in saving and borrowing decisions; for households with at least one financial institution. 1995 SCF.

Type of information $\%$ of $\mathrm{HH}$ using

for saving

$\%$ of $\mathrm{HH}$ using

for borrowing

0.1

43.2

2. Call around

3. Newspapers, magazines, television, radio

4. Friends, relatives, colleagues

5. Material in mail, advertisements

10.4

6. Financial planner, broker, accountant

7. Banker 26.8

2.5

17.6

0.5

9. Don't shop, always use same institution, past experience

10. Never save/borrow

13.0
0.8

\section{7}

16.7 will eventually dominate more traditional communication mechanisms. As indicated in Section III, the 1995 SCF asked households about the sources of information, including electronic media, they used for making decisions in these areas. This section examines the answers to these questions.

The rows of table 4 list nine general sources of information that households might use when making saving and borrowing decisions. Each of the columns reports the estimated percentages of households that use each source for making saving (column 1) and borrowing (column 2) decisions. ${ }^{25}$ Electronic sources of information (e.g. Internet and other online services) are the least used

Memo item:

11. Any response except "never save/borrow" or "don't shop, etc."

sources - only 0.3 percent of households say they use electronic sources for saving decisions, and only 0.1 percent for borrowing decisions. ${ }^{26}$ Interestingly, the next most rarely used source of information (ignoring the residual "other" category) is bankers. Only about two and a half percent of households say they use a banker as a source of information for either saving or borrowing decisions. ${ }^{27}$

\footnotetext{
${ }^{25}$ These data are displayed in Figure 15.

${ }^{26}$ Because such electronic sources were not explicitly enumerated in the underlying survey questions, all such responses were reported as an "other" source and coded separately after the interview.

${ }^{27}$ This result contrasts sharply with a recent paper by Kennickell, Starr-McCluer and Sunden [1996] that uses the 1983 SCF to examine household sources of financial advice. According to that survey, 26 percent of all
} 
The most popular sources of information for saving and borrowing decisions are calling around (row 2) and friends, relatives, and colleagues (row 4). A full 43 percent of households say they call around for information to aid them with borrowing decisions. Newspapers, magazines, $\mathrm{TV}$, and radio are also used frequently (by about 25 percent of households), as are financial planners, brokers, and accountants. Advertisements and materials received in the mail are used fairly often for borrowing decisions, but with much lower frequency for saving decisions. Still, some 10 percent of households report that they use advertisements or material received in the mail to help them make saving decisions. Fourteen percent of households say they do not shop around, always rely on the same institution, or use past experience (row 9) for saving decisions, but only 5.7 percent of households give this response for borrowing decisions. This asymmetry in response rates suggests that households are relatively more tied to their existing financial institution for asset side (e.g., savings deposit) services than for liability (e.g., credit) services, and is consistent with research that has examined this issue more directly. ${ }^{28}$

Figures 16 through 19 examine the relationship between the types of information used and households' median income, level of financial assets, age, and years of education. ${ }^{29}$ Looking first at Figure 16, it is remarkable that for all the sources of information except electronic and banker, the median income of users is always higher than that of nonusers. For electronic sources of information, the median income of users is higher for saving decisions, but not for borrowing decisions. Users of bankers have about the same or a little lower median income as nonusers. With respect to financial assets (Figure 17), the patterns are similar, but the differences between the financial assets of users and nonusers are sometimes quite a bit larger than is the case for income. This is especially true for users of traditional media (newspapers, magazines, TV, and radio), advertisements and material received in the mail (for saving decisions), and users of financial planners brokers, and accountants. In general, financial assets seem to differentiate

households reported using a banker for such advice. The difference is driven, in part, by differences in the questions asked in the two surveys. The 1983 survey asks directly for any use of bankers, while the 1995 survey does not ask explicitly about bankers. Rather, as in the case of electronic sources, respondents in 1995 could identify bankers as any "other" source of financial advice. Nevertheless, the difference is so large that it suggests an interesting area for future research.

${ }^{28}$ See Kwast, Starr-McCluer, and Wolken (1996).

${ }^{29}$ The data underlying these charts are given in Appendix tables 3a and $3 \mathrm{~b}$. 
between users and nonusers of the various sources of information better for saving decisions than for borrowing decisions.

Users of most sources of information tend to be somewhat younger than nonusers (Figure 18). This is especially true of users of electronic sources of information, who tend to be considerably younger than nonusers for both saving and borrowing decisions. Indeed, the median age of users of electronic information for saving decisions is 12 years less than that of nonusers, and for borrowing decisions is an astounding 20 years less than that of nonusers. Bankers are, once again, an interesting exception to this general point. The median age of household heads who say they use a banker as a source of information for saving decisions is the same as that for nonusers, and five years higher than that of nonusers for borrowing decisions. Households that do not shop around and always use the same institution or past experience also tend to be substantially older than households that do not report such behavior. ${ }^{30}$

The median educational level of users of electronic sources of information (Figure 19) for both saving and borrowing decisions is a striking three years higher than that of nonusers. Perhaps even more remarkable, the median user of electronic information has a college degree. Users of traditional media, the mail and other advertisements, and financial planners, brokers, and accountants also are better educated than nonusers. However, none of the median users in these groups has more than two years of college. In contrast, users and nonusers of calling around, friends, relatives and colleagues, and banks tend to have comparable educational levels, and these levels are below those of users of the other sources of information.

The bottom two panels of table 3 summarize multivariate probit regressions that examine the use of the sources of information considered here. Looking first at the income column, the probits estimate that while income has some independent effect on the choice of sources of information used for saving decisions, it has no significant effect on the probability of use of any of the sources of information for borrowing decisions. The correlation with financial assets is stronger for the use of information sources for both saving and borrowing decisions. Higher levels of financial assets increase a household's probability of using sources derived from calling

\footnotetext{
${ }^{30}$ See Appendix tables $3 \mathrm{a}$ and $3 \mathrm{~b}$.
} 
around, newspapers and other traditional media, and from a financial planner, accountant, or broker for both saving and borrowing decisions (and for using advertisements or material received in the mail for saving decisions). Interestingly, financial assets are estimated to have no effect on the probability of using information derived from electronic sources or bankers for either saving or borrowing decisions. Financial assets have no effect of the probability of using friends, relatives, and colleagues as sources of information for saving decisions, but higher assets lower the probability of using such sources for borrowing decisions. Finally, financial assets have no effect on the probability of using ads or material in the mail as sources of information for household borrowing decisions.

The probits also support the view that age can play a significant role in a household's choice of the source of information it uses for financial decisions. Greater age increases the probability of using a banker as a source of information for borrowing decisions. In contrast, age is estimated to have no effect on the use of a banker for saving decisions. Higher age is associated with a lower probability of calling around, using advice from friends, relatives, and colleagues, and using advertisements or material in the mail for either saving or borrowing decisions. Age is also negatively correlated with using electronic sources for saving decisions, or using newspapers and other traditional media for borrowing decisions.

As with all of the other hypotheses examined in this paper, the probits estimate that education plays a significant role in a household's choice of virtually all the sources of information. Greater education increases the probability a household will use all of the sources of information considered here, with two notable exceptions. First, education has no effect on the probability of using an electronic source for borrowing decisions. Second, more education has no effect on a household's decision to use a banker's help in making saving decisions, and decreases the probability it will use a banker to help it make borrowing decisions. ${ }^{31}$

\footnotetext{
${ }^{31}$ A final set of probits, not reported here, considered the relationship between the probability of using different sources of information for saving or borrowing decisions and whether a household used one or more types of electronic instruments, or used some type of electronic service at a financial institution. However, the results of these probits were very difficult to interpret, and suggest that investigation of such relationships will require the development of more structural hypotheses - a fertile topic for future research.
} 


\section{Conclusion}

This study has used the 1995 Survey of Consumer Finances to get a detailed look at the extent of use, and the characteristics of households that use electronic and other technologies to conduct business with their financial institutions, and electronic and other sources of information for making saving and borrowing decisions. While the most common technology used to conduct business with a financial institution is the in person visit, it is estimated that about 70 percent of U.S households use some form of a fairly narrowly defined set electronic technologies. However, the most commonly used instrument — direct deposit — is a relatively old and well-established electronic technology. More recent electronic instruments are used by much smaller proportions of households. The most popular sources of information for saving and borrowing decisions are calling around and friends, relatives, and colleagues. Well under one percent of households name an electronic source of information for help in making such decisions. Thus, while these results support the view that household use of electronic media to transact with a financial institution is fairly, and perhaps increasingly common, the use of electronic sources of information for financial decision-making is barely off the ground.

Income, the level of financial assets, age, and education all play important roles in categorizing a household's use of electronic and other media. In general, financial assets, age, and education tend to be more important independent factors than income, which is highly collinear with these variables. With regard to the use of electronic media, households with incomes below $\$ 25,000$ per year seem particularly unlikely to use electronics, and households with annual incomes above $\$ 50,000$ seem relatively likely to do so. Households with larger financial assets are much more likely to use electronic media.

Age has a somewhat mixed effect on the use of electronic technologies although it does appear that household heads under the age of 35 are considerably more likely to use the computer (and ATMs and debit cards). In addition, the only use of electronic technology that increases with age is direct deposit, a reflection of the importance of direct deposit of Social Security checks. It appears difficult to overestimate the importance of education in describing the use of electronic products and services at financial institutions. Use of electronics is consistently and positively associated with years of education. An important break point seems to be achieving at 
least a college degree, an educational level currently held by less than one-third of U.S. households.

These results suggest a number of interesting interpretations and speculations. We conclude with three. First, the importance of income, financial assets, and education for using electronic media suggests that the potential market for many of these products is still highly specialized. Second, the general reluctance of lower income, lower financial assets, older, and less educated households to voluntarily use electronic media suggests that the upcoming mandated use of electronic deposits for Social Security, federal government pension, and welfare payments is likely to meet with some resistance, unless carefully designed to assuage the concerns of these groups. This speculation is reinforced by the fact that 25 percent of U.S. households with annual incomes below $\$ 25,000$ report that they do not have a deposit account at a financial institution. Another interesting aspect of our results is the apparent role of banks as sources of information for household saving and borrowing decisions. Banks are the second least reported source of information, just ahead of electronic media. Moreover, users of banks for such information tend to be older and less educated than other households. Thus, while other research suggests that almost all U.S. households that conduct business with a financial institution have an account at a bank or other insured depository, the results of this paper suggests that banks have not been very successful at becoming a major source of financial information for these customers. 


\section{References}

Bank for International Settlements. Statistics on Payment Systems in the Group of Ten

Countries. Basle, Switzerland, December 1995.

Blinder, Alan S. "Statement before the Subcommittee on Domestic and International

Monetary Policy of the U.S. House of Representatives," Federal Reserve Bulletin, vol. 81

(December 1995), pp. 1089-1092.

Booz-Allen and Hamilton, Inc. Consumer Demand for Internet Banking, Financial Services

Group, New York (July 1996).

. Internet Banking in Europe: A Survey of Current Use and Future Prospects,

London (July 1996).

Internet Banking: A Survey of Current and Future Development, Financial

Services Group, New York (February 1996).

Congressional Budget Office. Emerging Electronic Methods for Making Payments.

Washington: Government Printing Office, June 1996.

Grant Thornton. Banking on the Internet: Experience vs. Expectations, Washington, D.C. (July 1996).

Arthur B. Kennickell, Myron L. Kwast, and Martha Starr-McCluer. "Households' Deposit Insurance Coverage: Evidence and Analysis of Potential Reforms," Journal of Money, Credit and Banking, (August 1996) pp.311-322.

, Martha Starr-McCluer, and Annika E. Sundén. "Financial Advice and Household

Portfolios," mimeo, Board of Governors of the Federal Reserve System, Washington,

D.C. (August 1996).

, and "Family Finances in the U.S.: Recent Evidence

from the Survey of Consumer Finances," Federal Reserve Bulletin, (January 1997)

pp. 1-24.

and R. Louise Woodburn. “Consistent Weight Design for the 1989, 1992 and 1995

SCFs, and the Distribution of Wealth," mimeo, Board of Governors of the Federal Reserve System, Washington, D.C. (June 1997). 
Kwast, Myron L., Martha Starr-McCluer, and John D. Wolken. "Market Definition and the Analysis of Antitrust in Banking, The Antitrust Bulletin (forthcoming). 


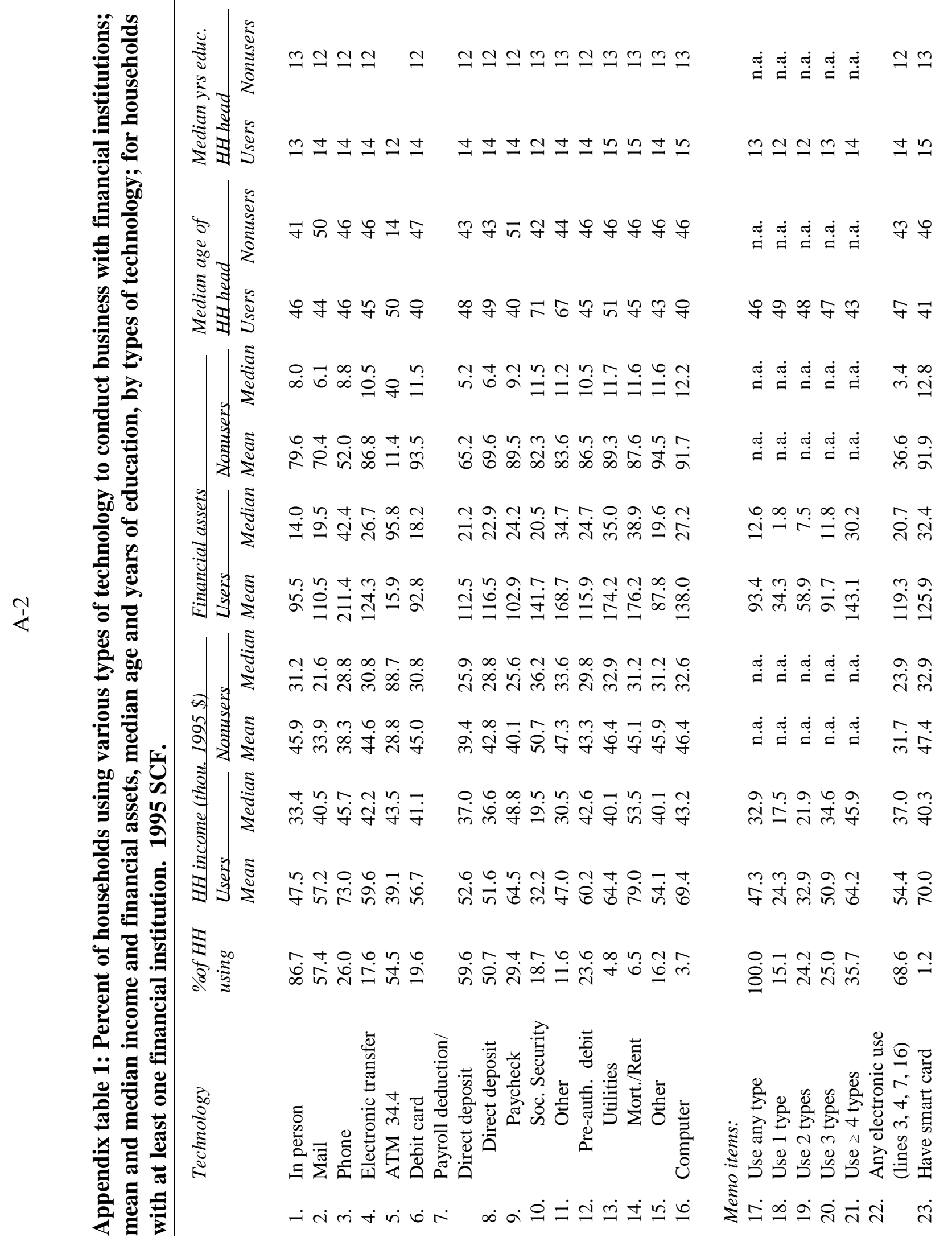




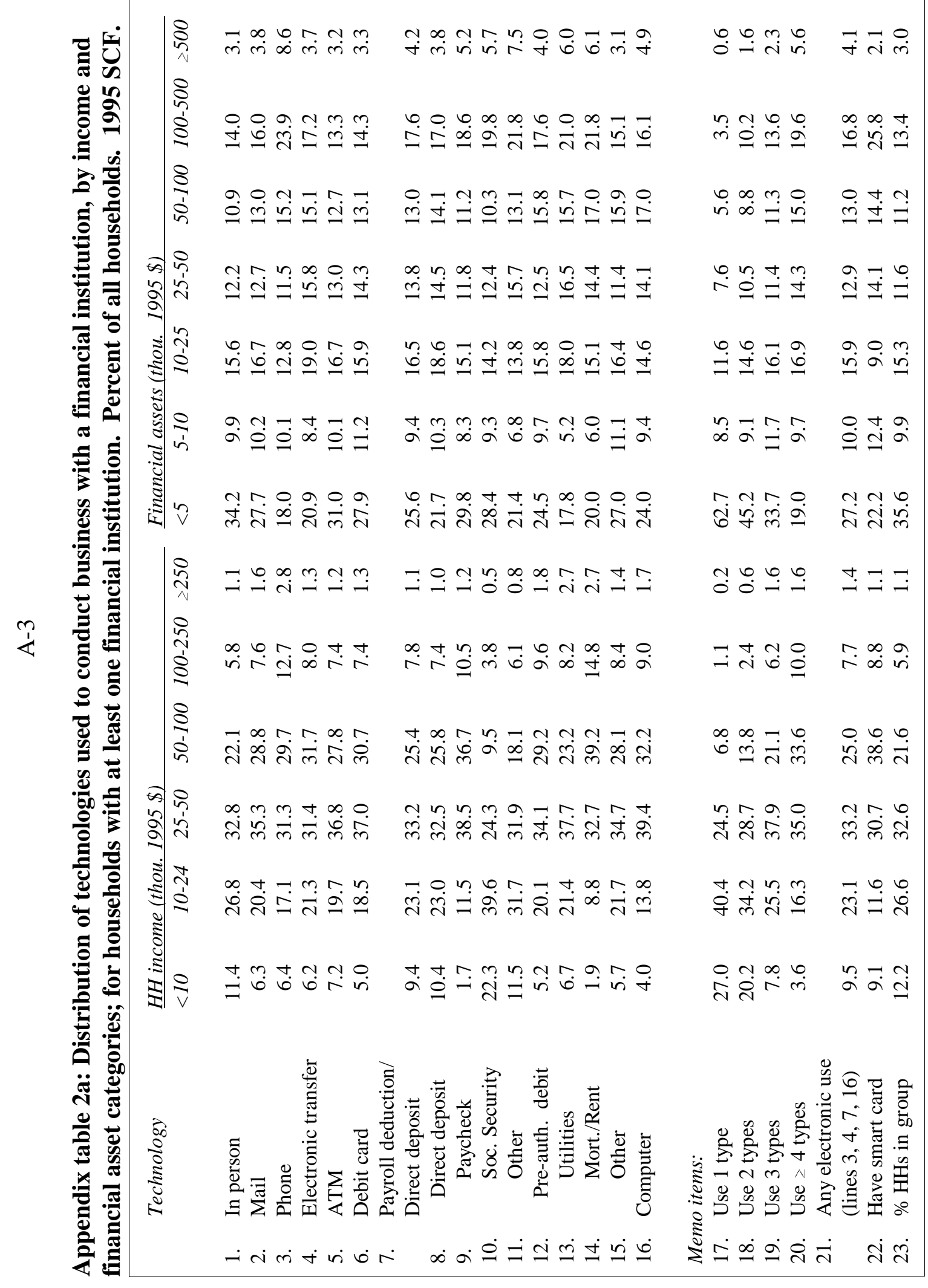




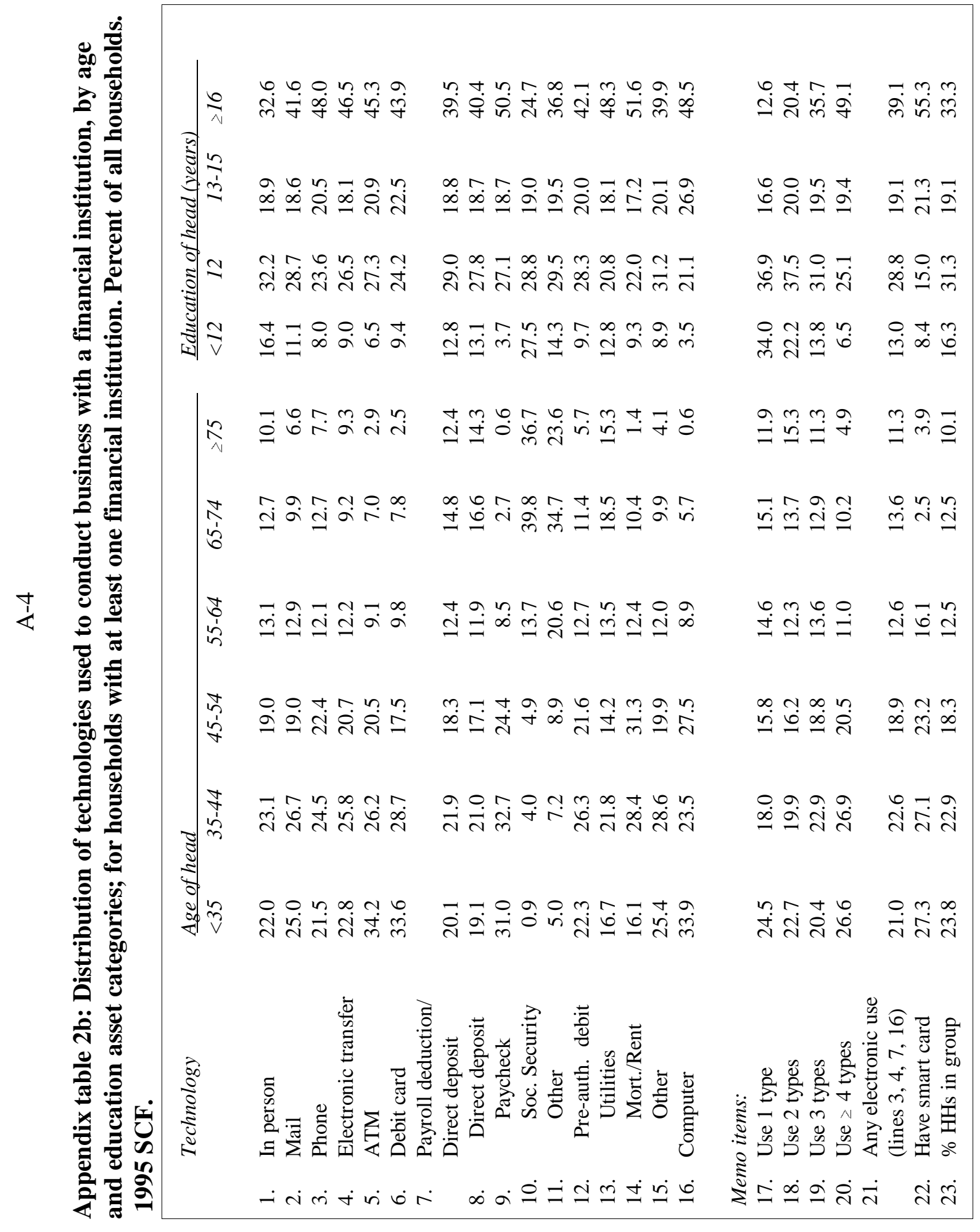




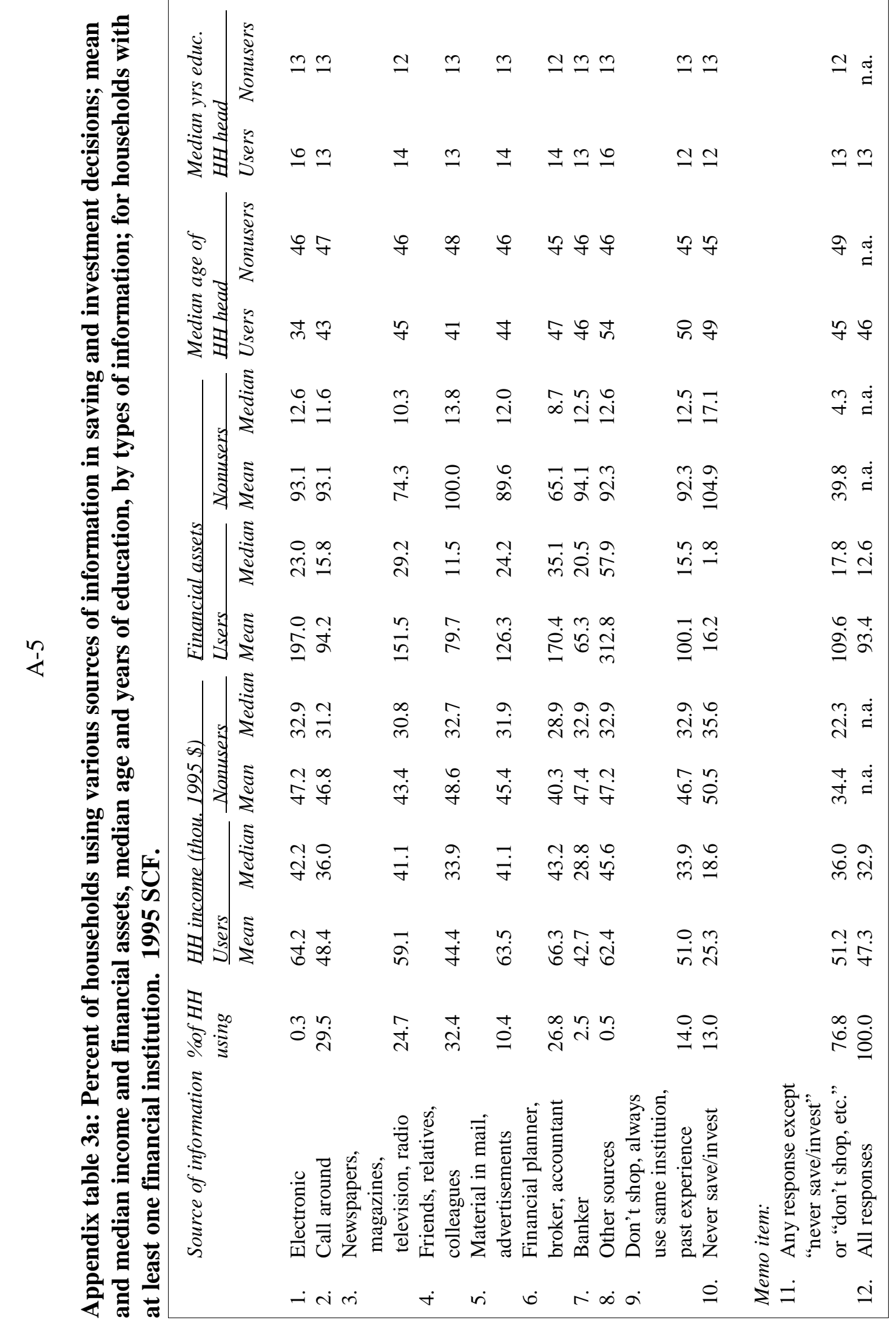




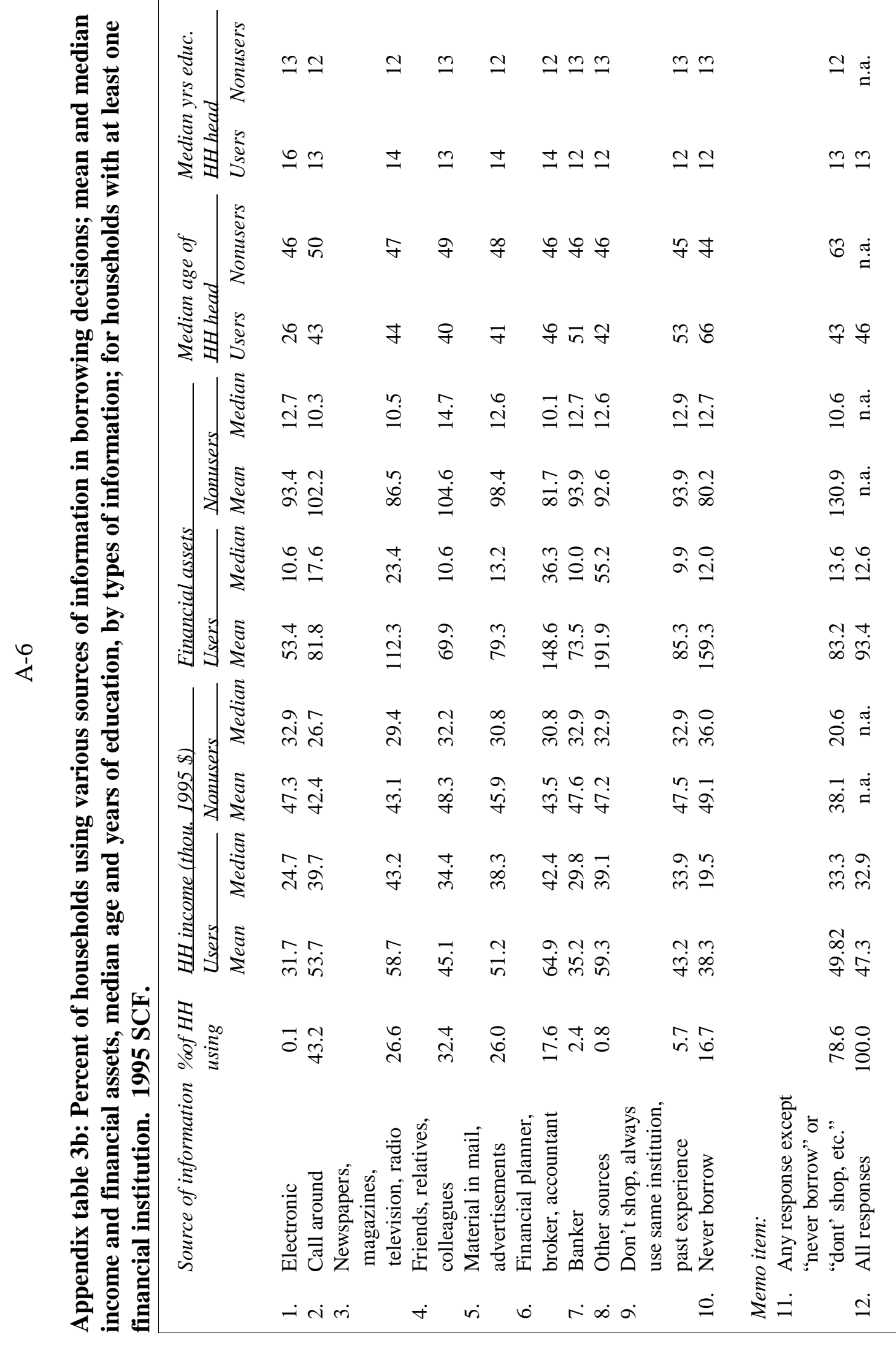




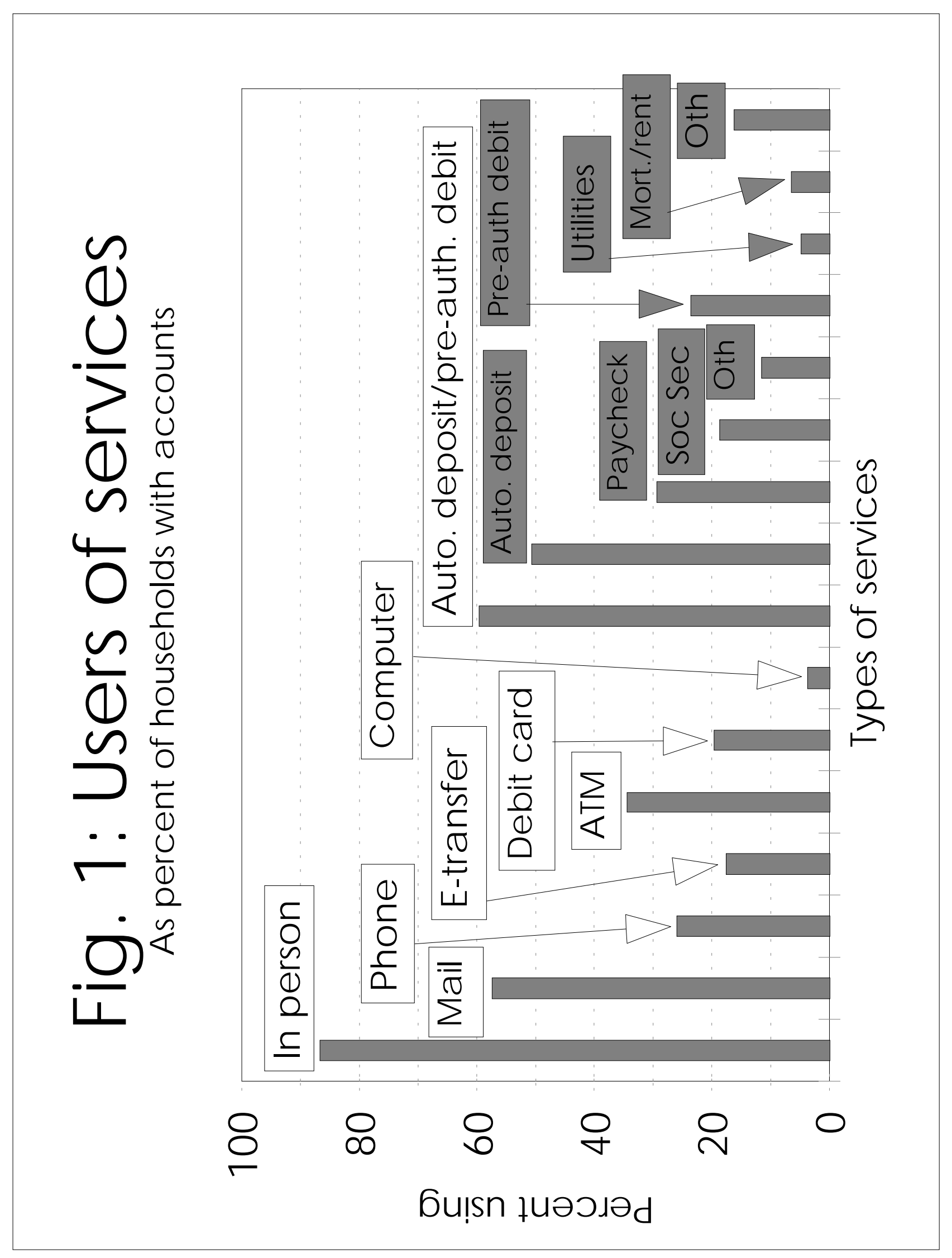




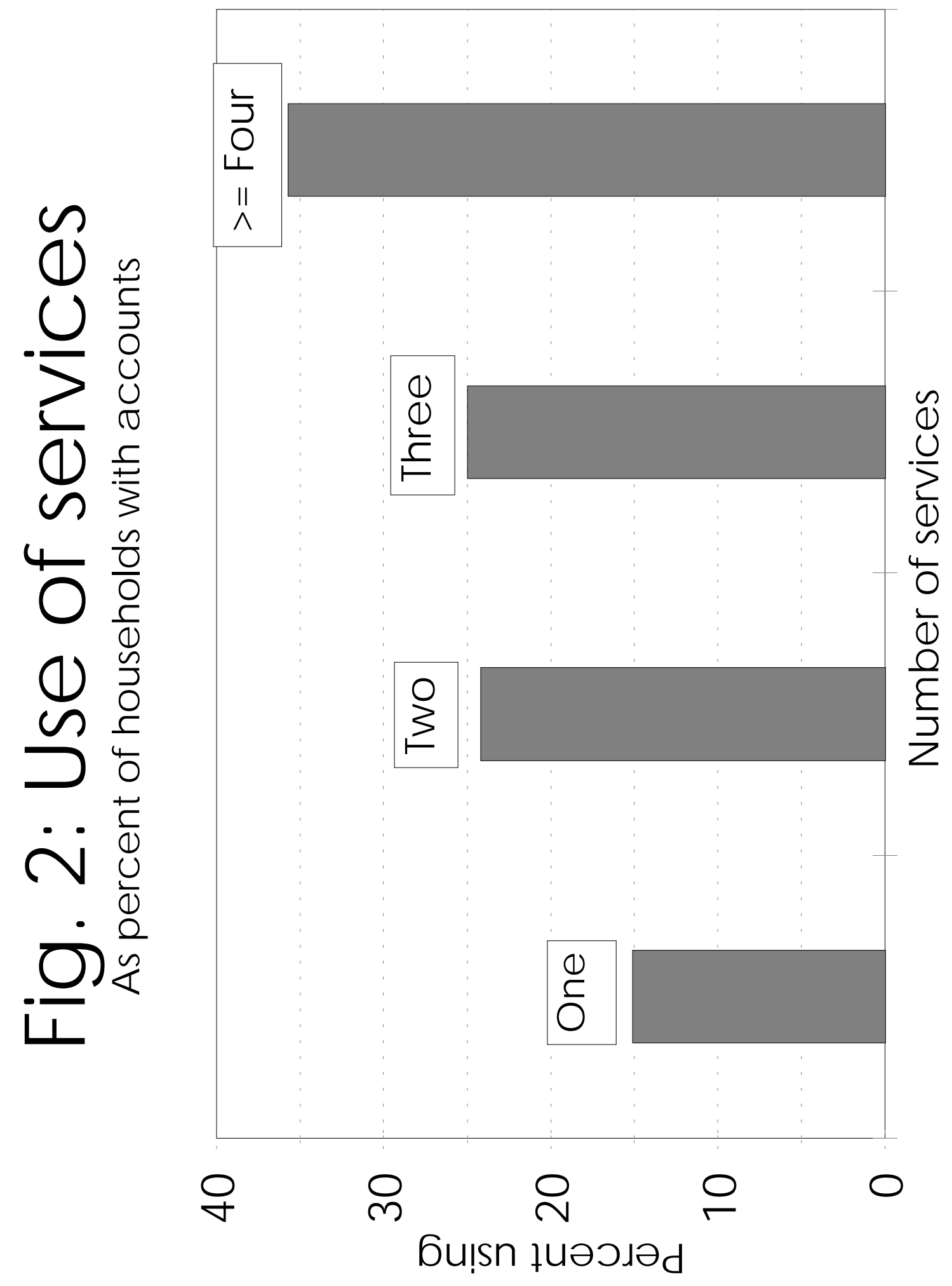




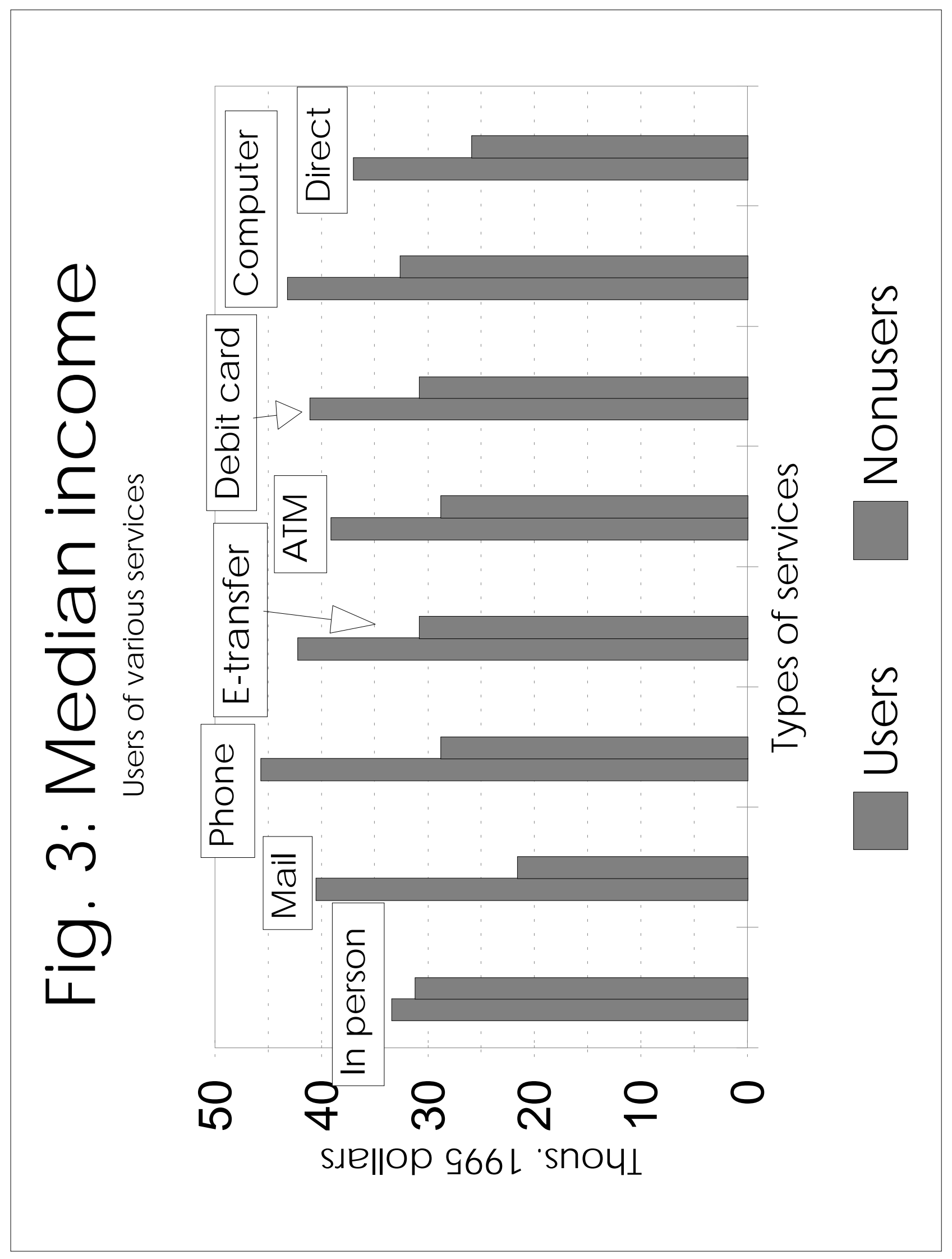




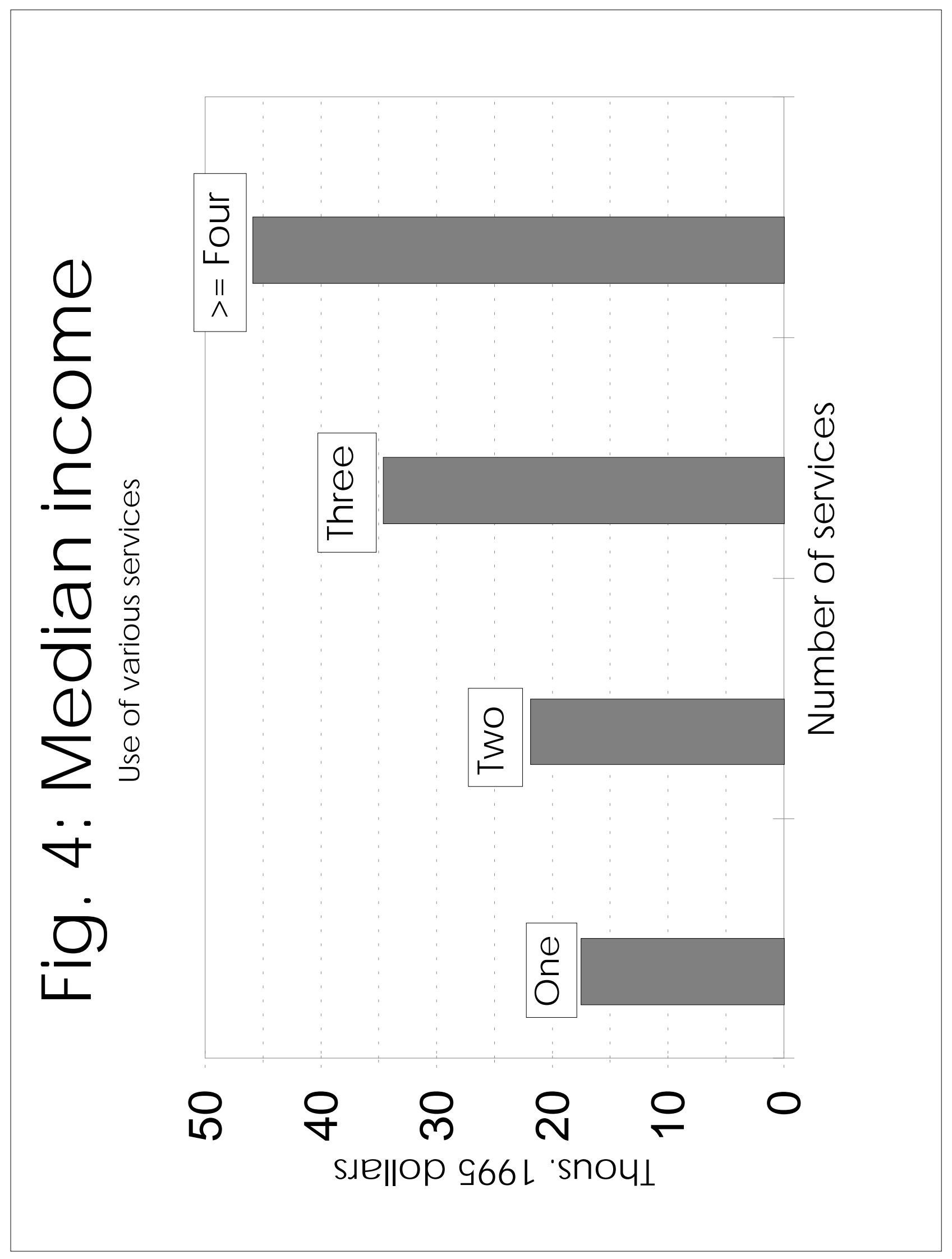




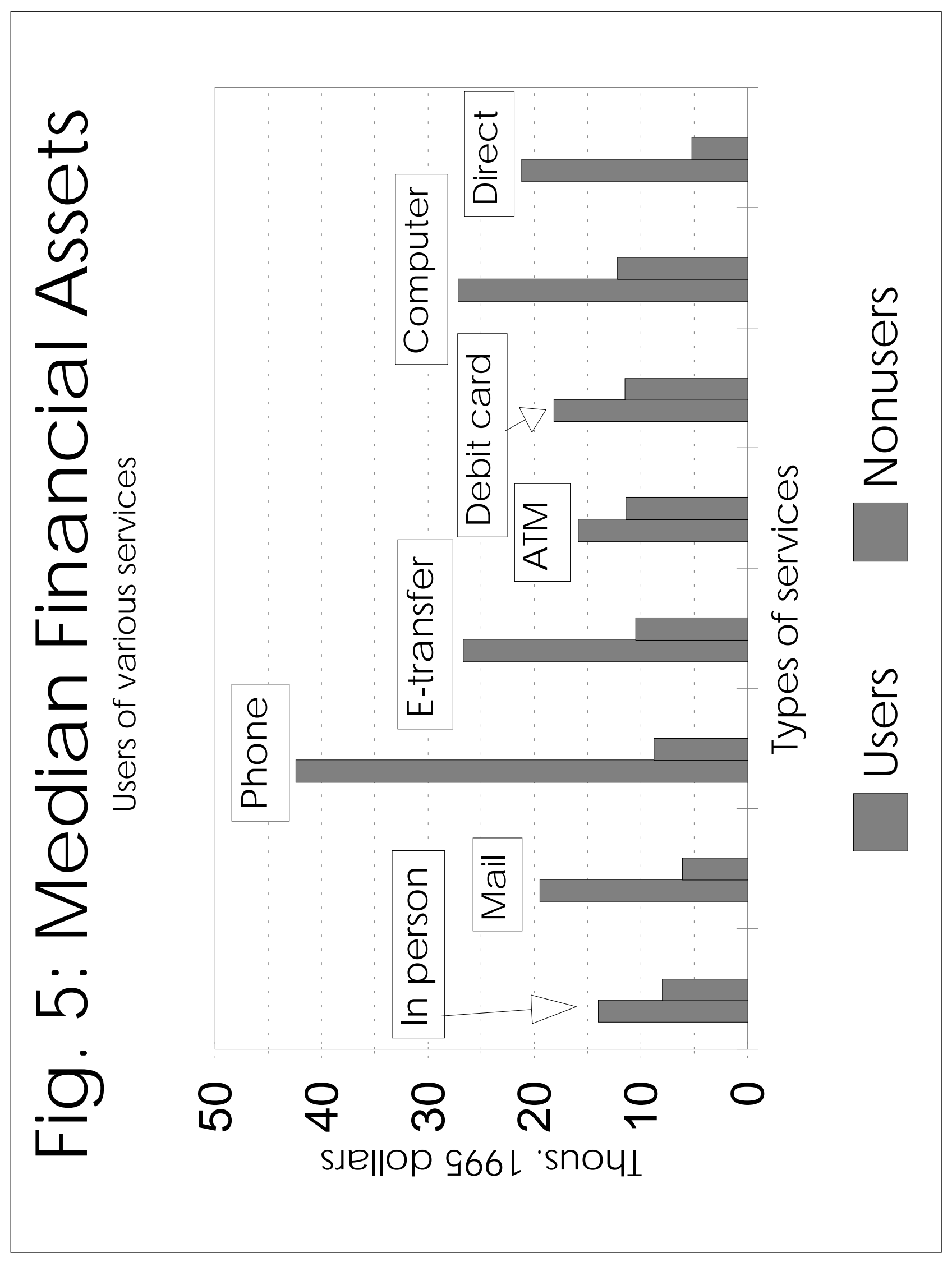




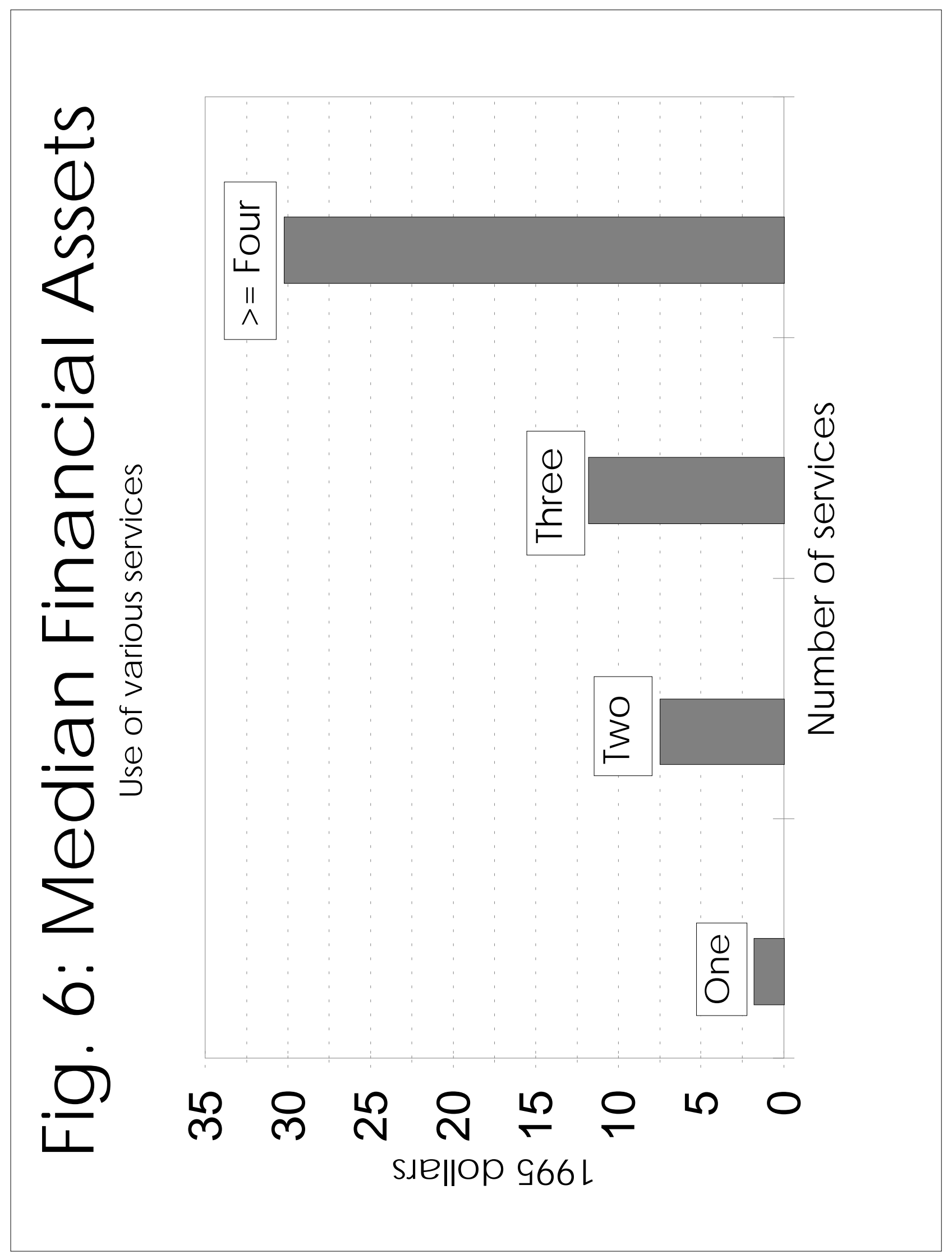




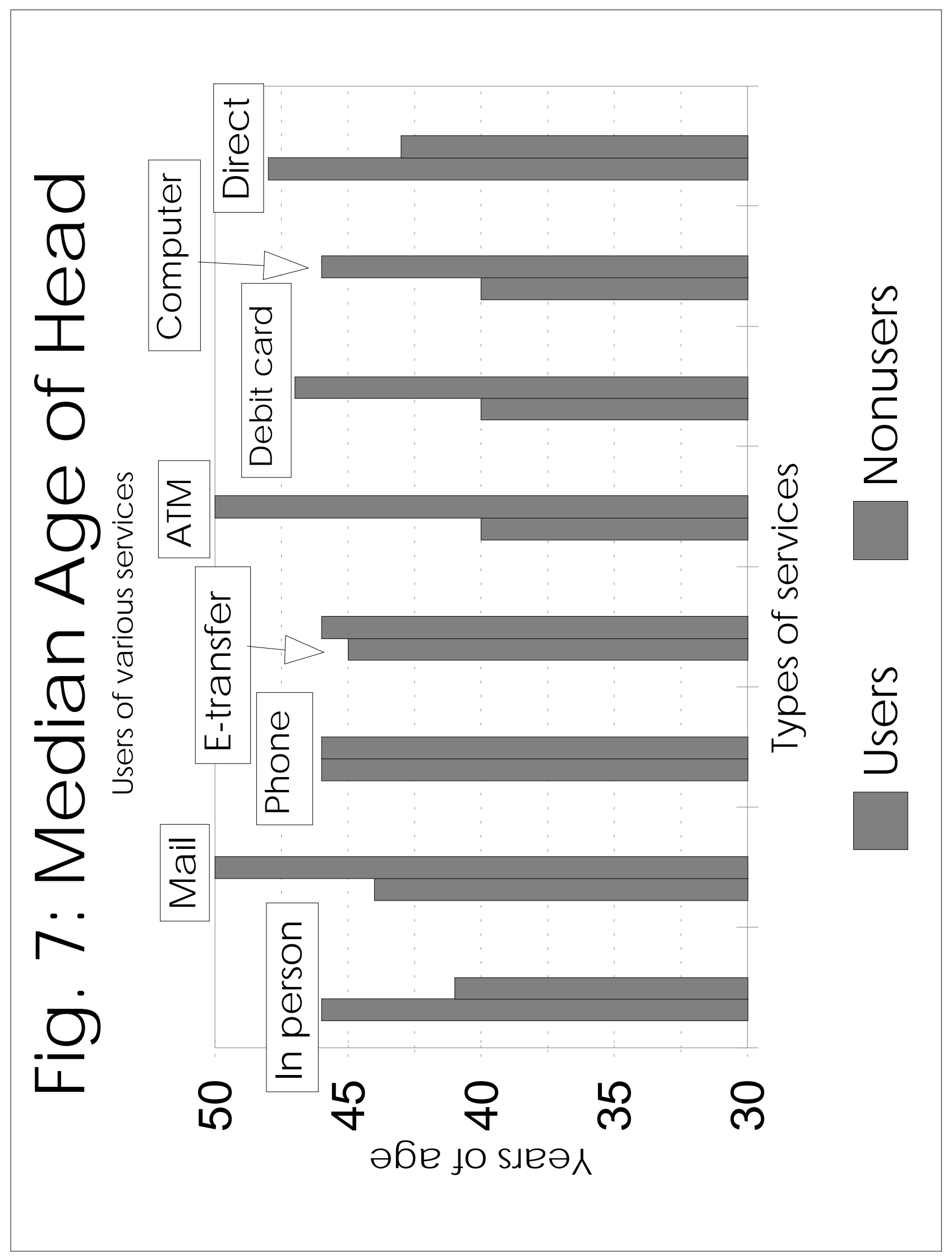




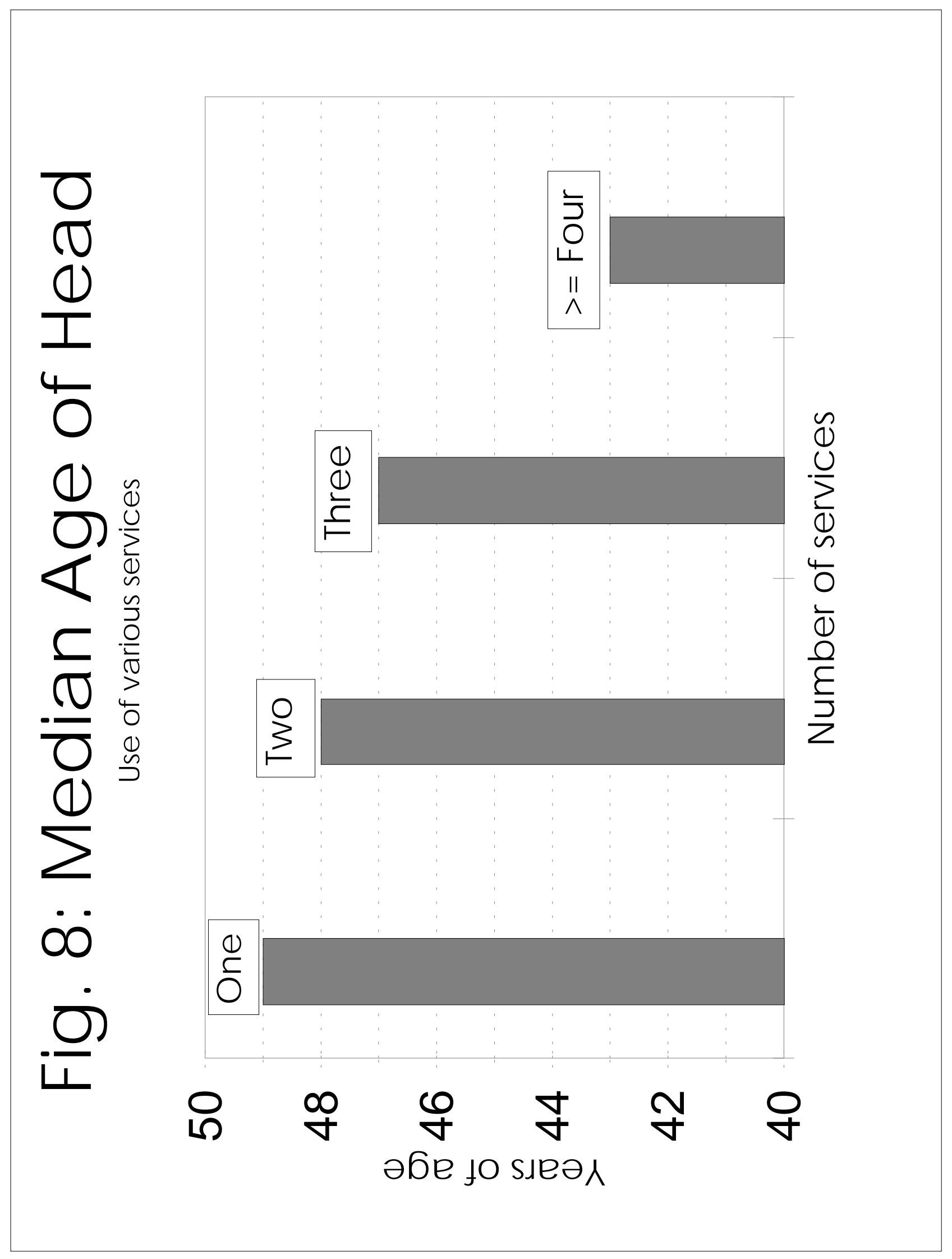




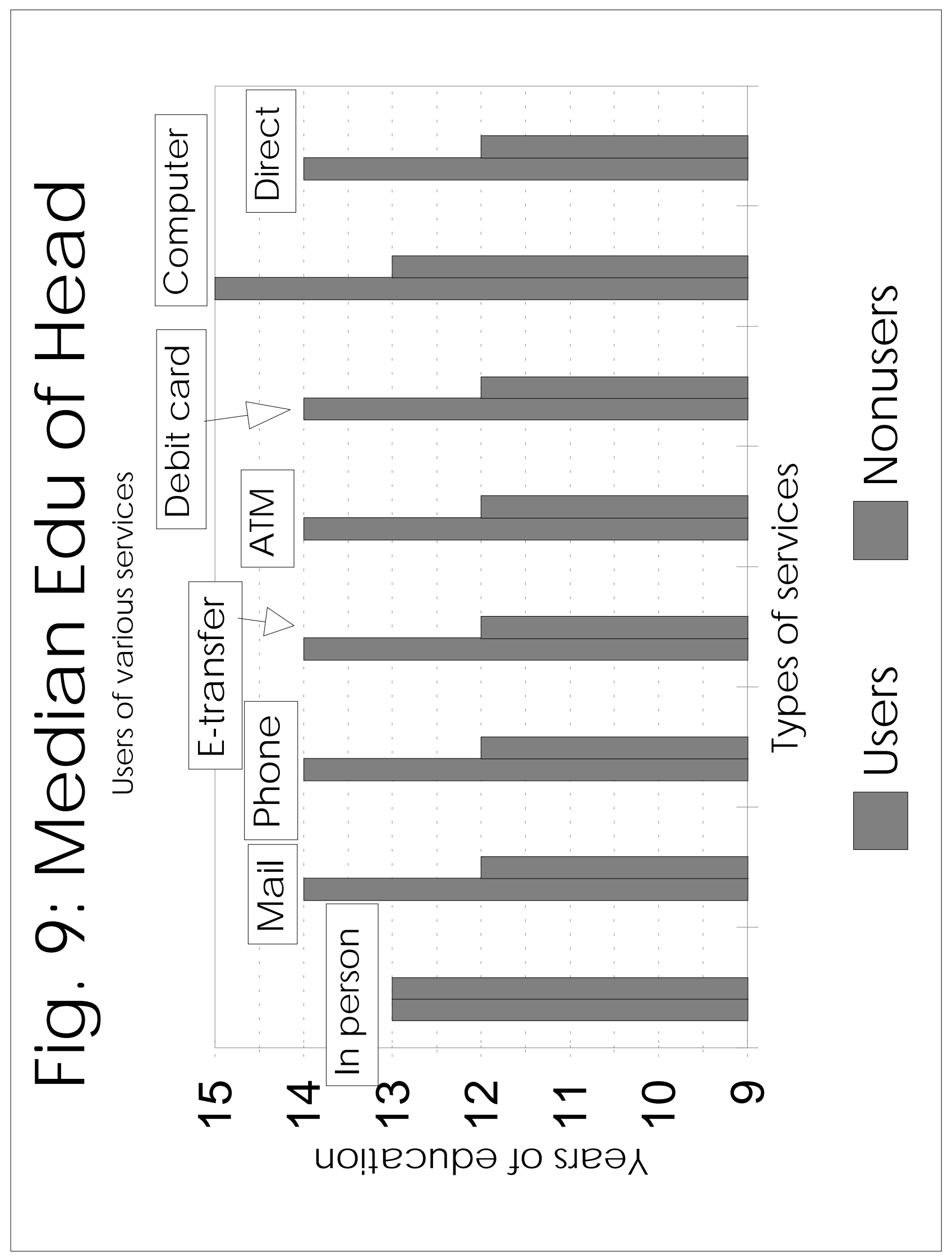




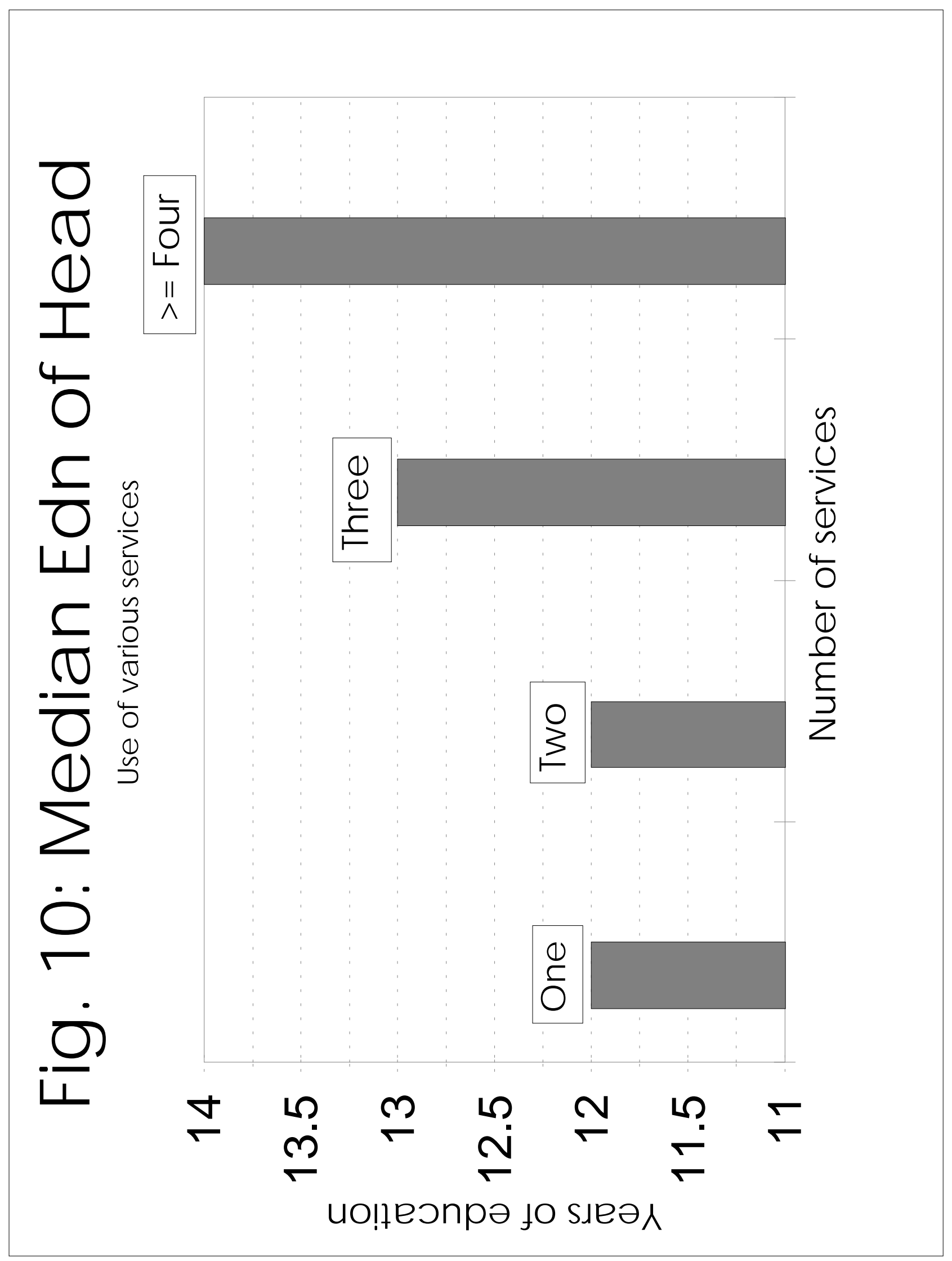



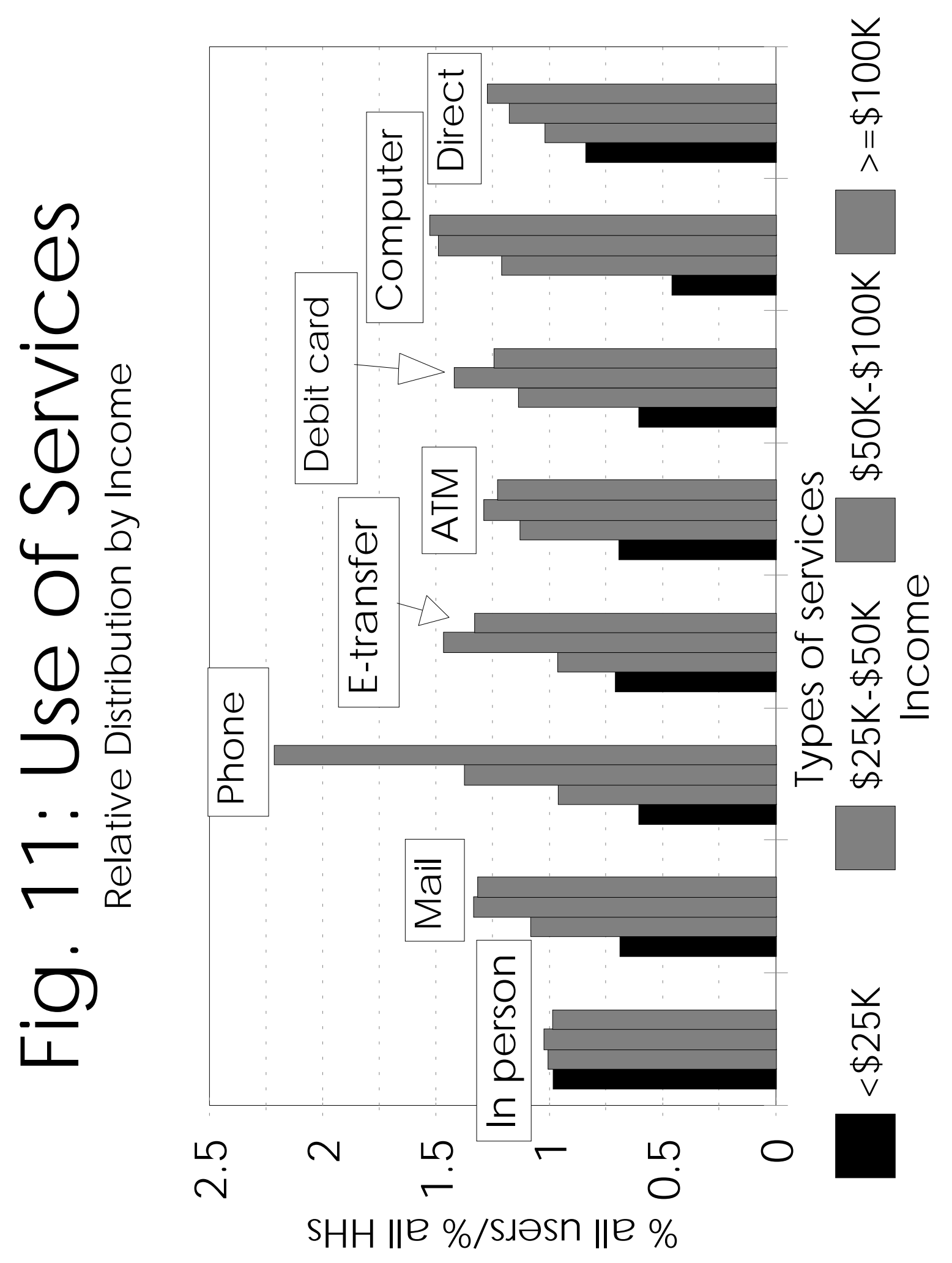


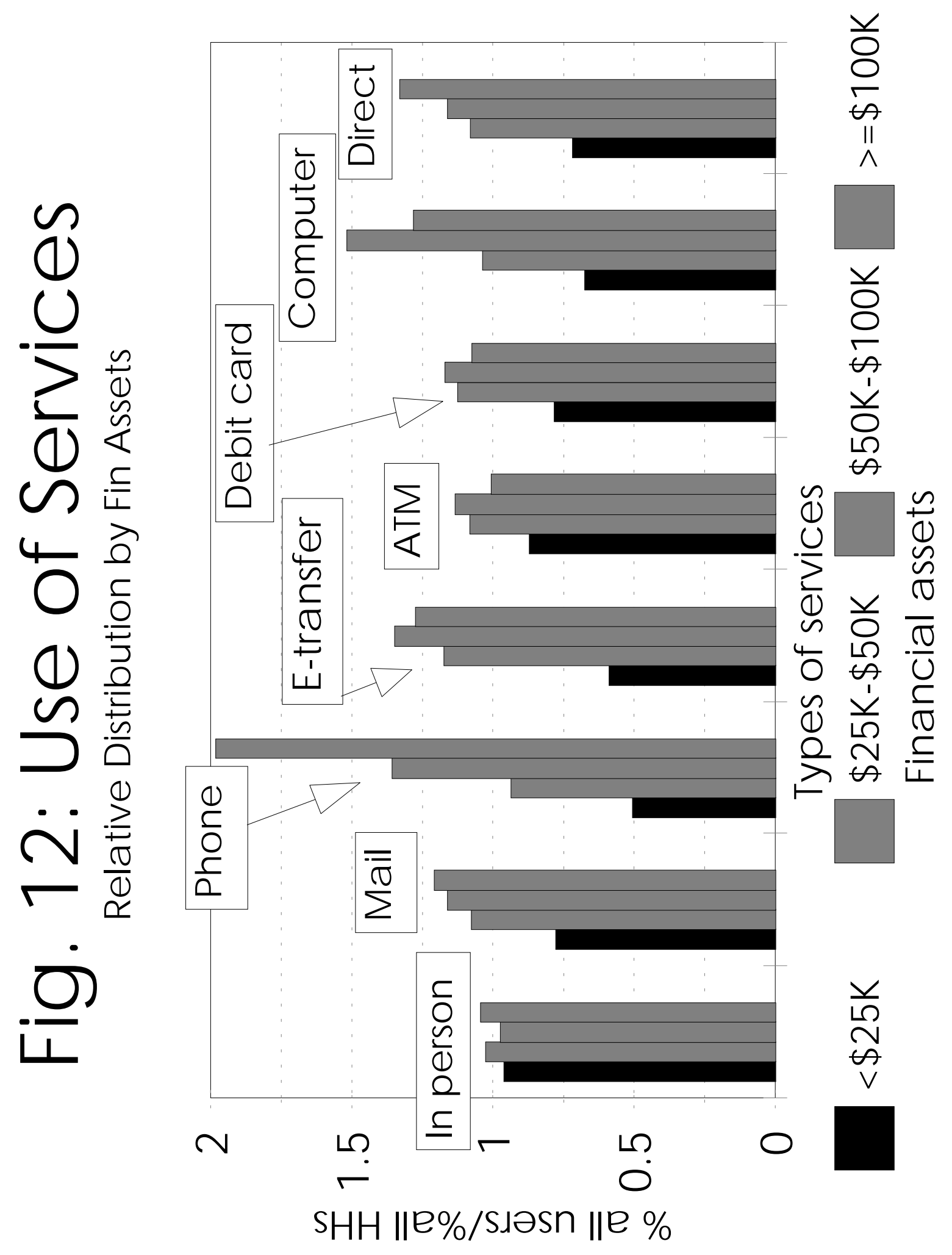




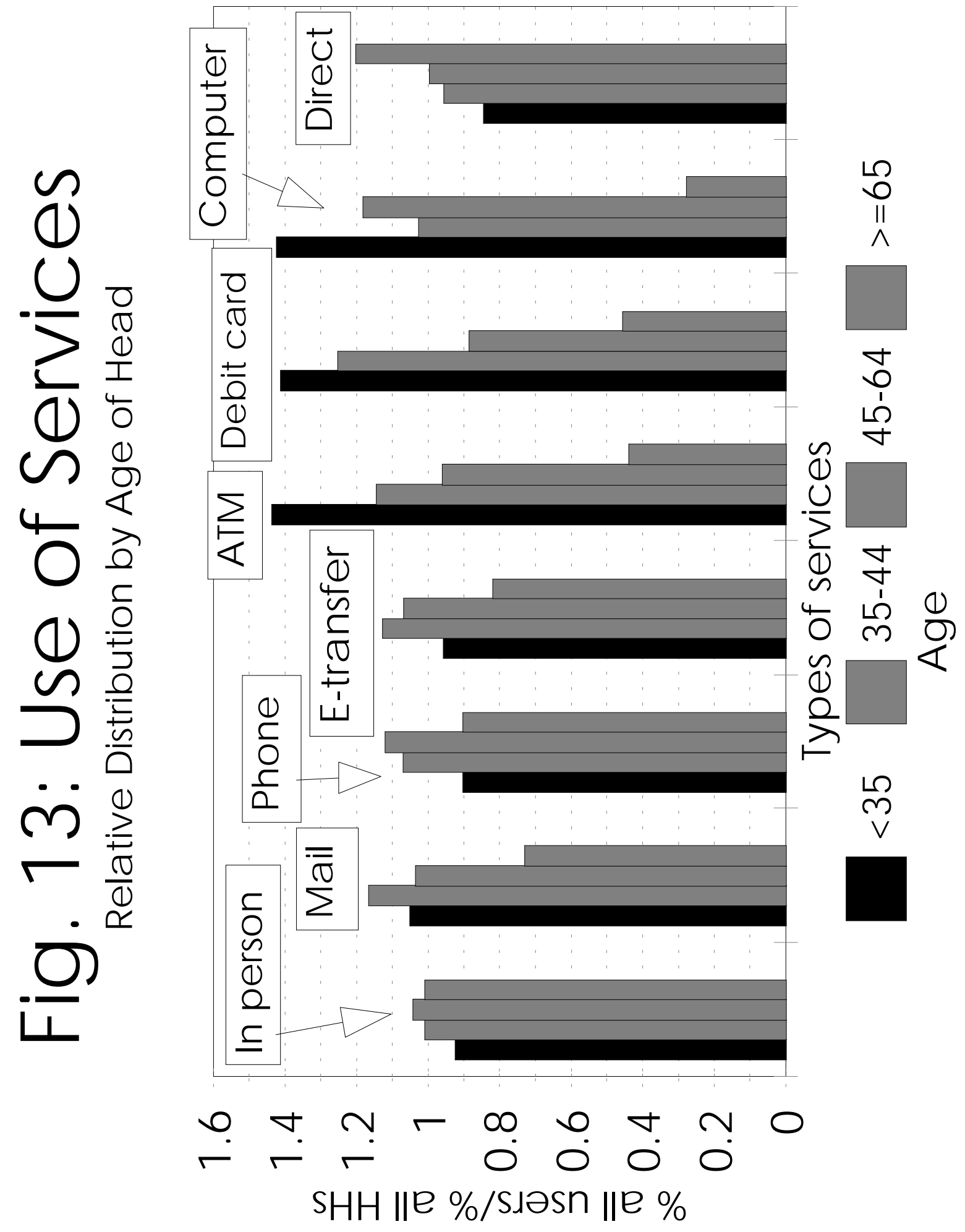




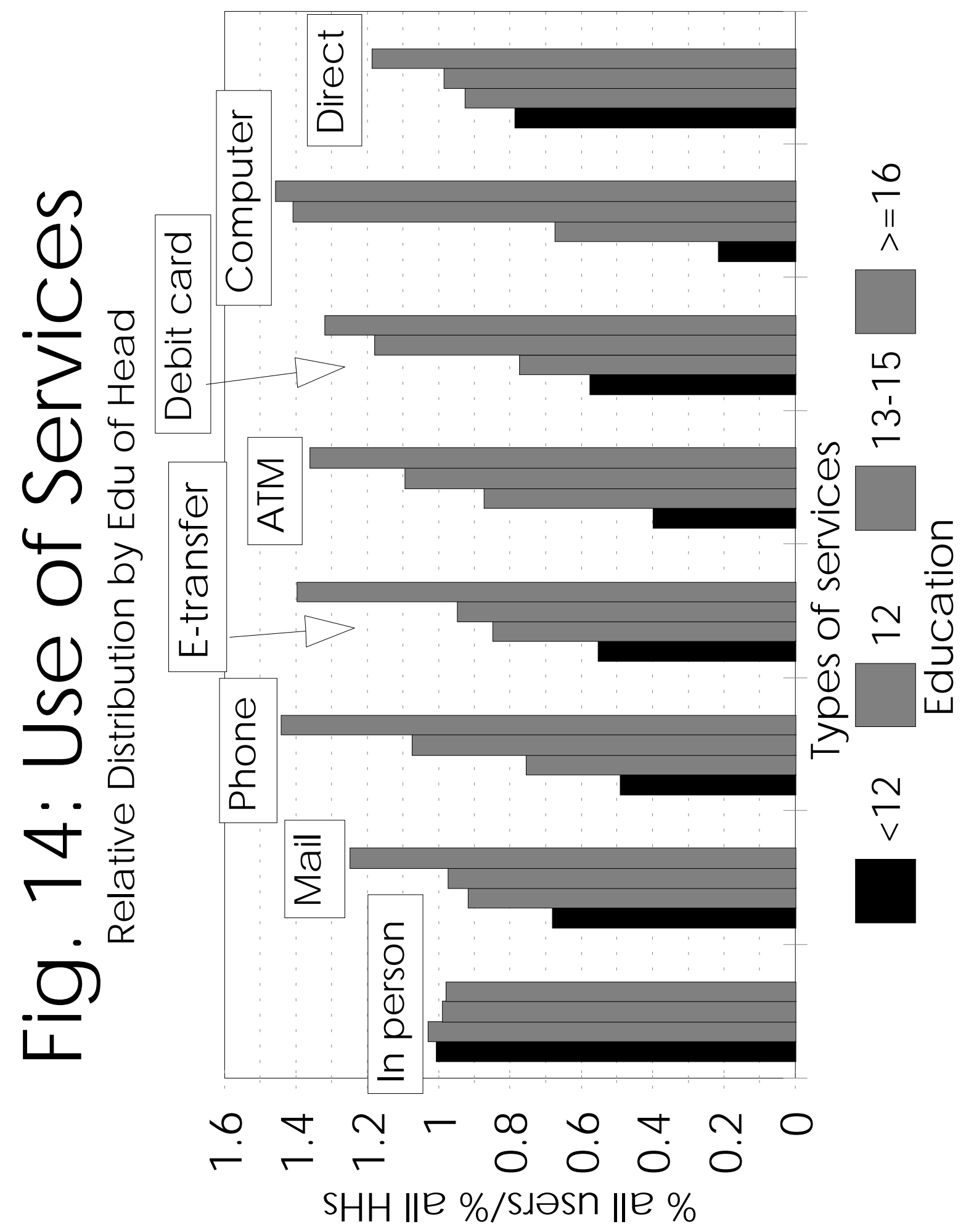




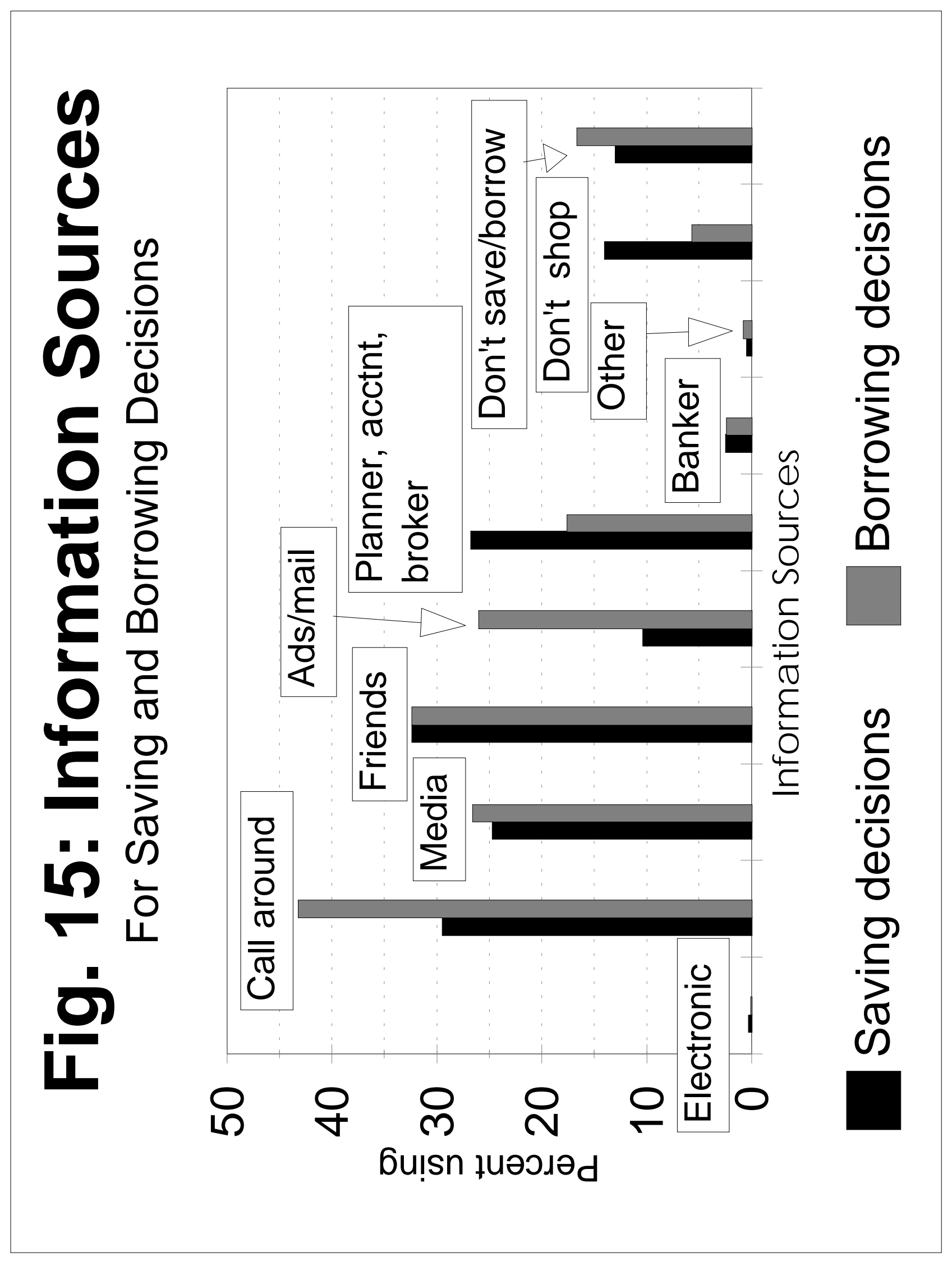




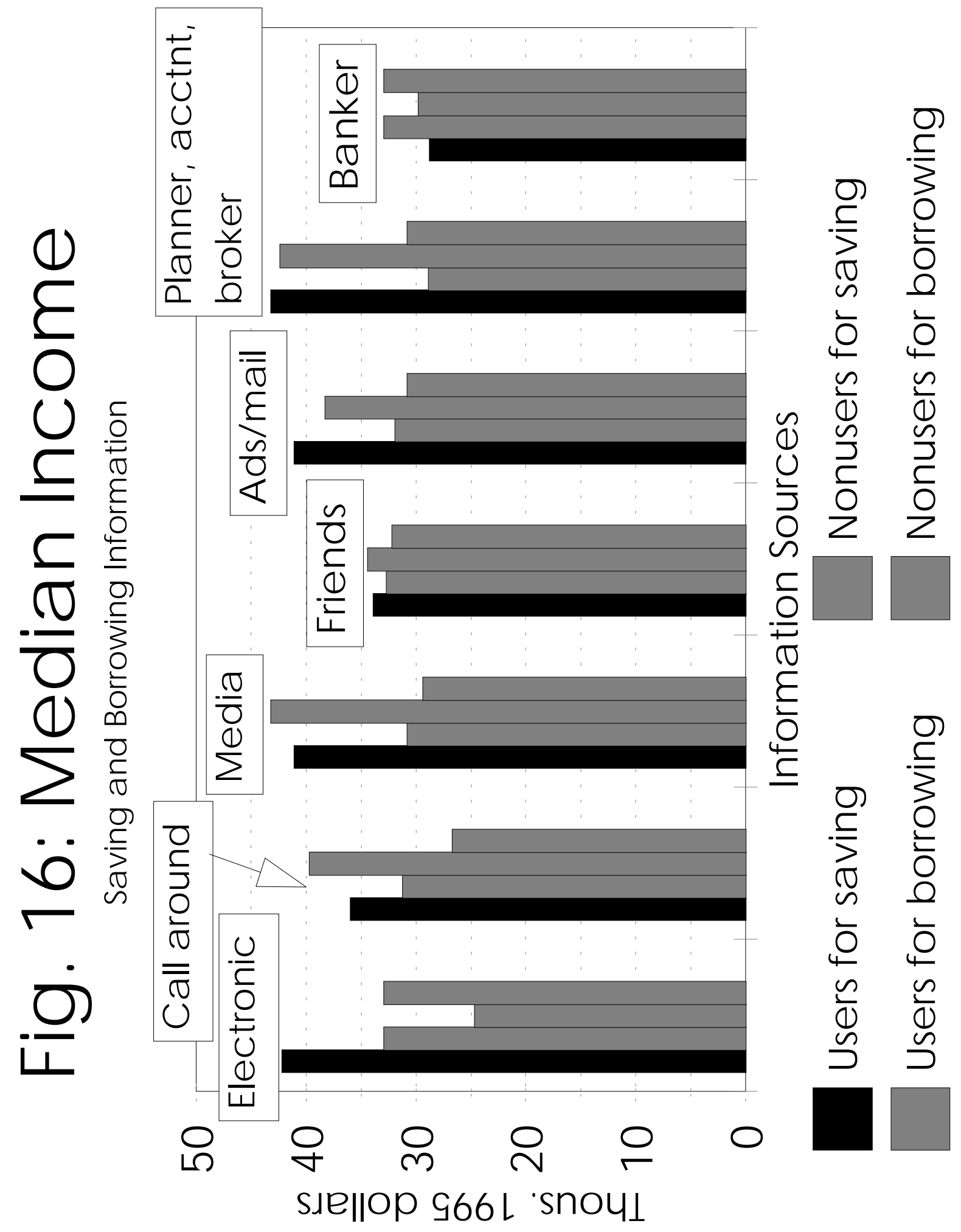




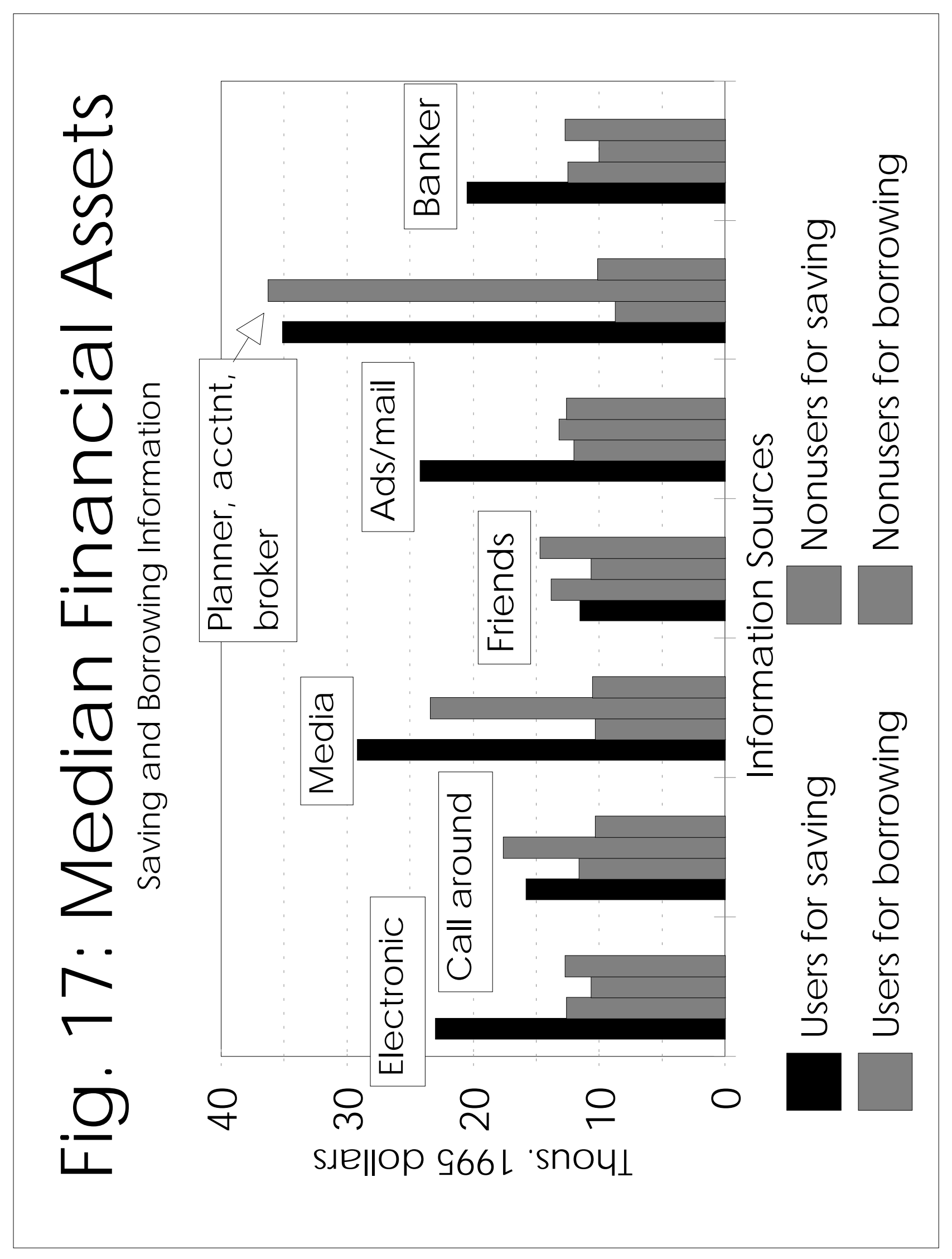




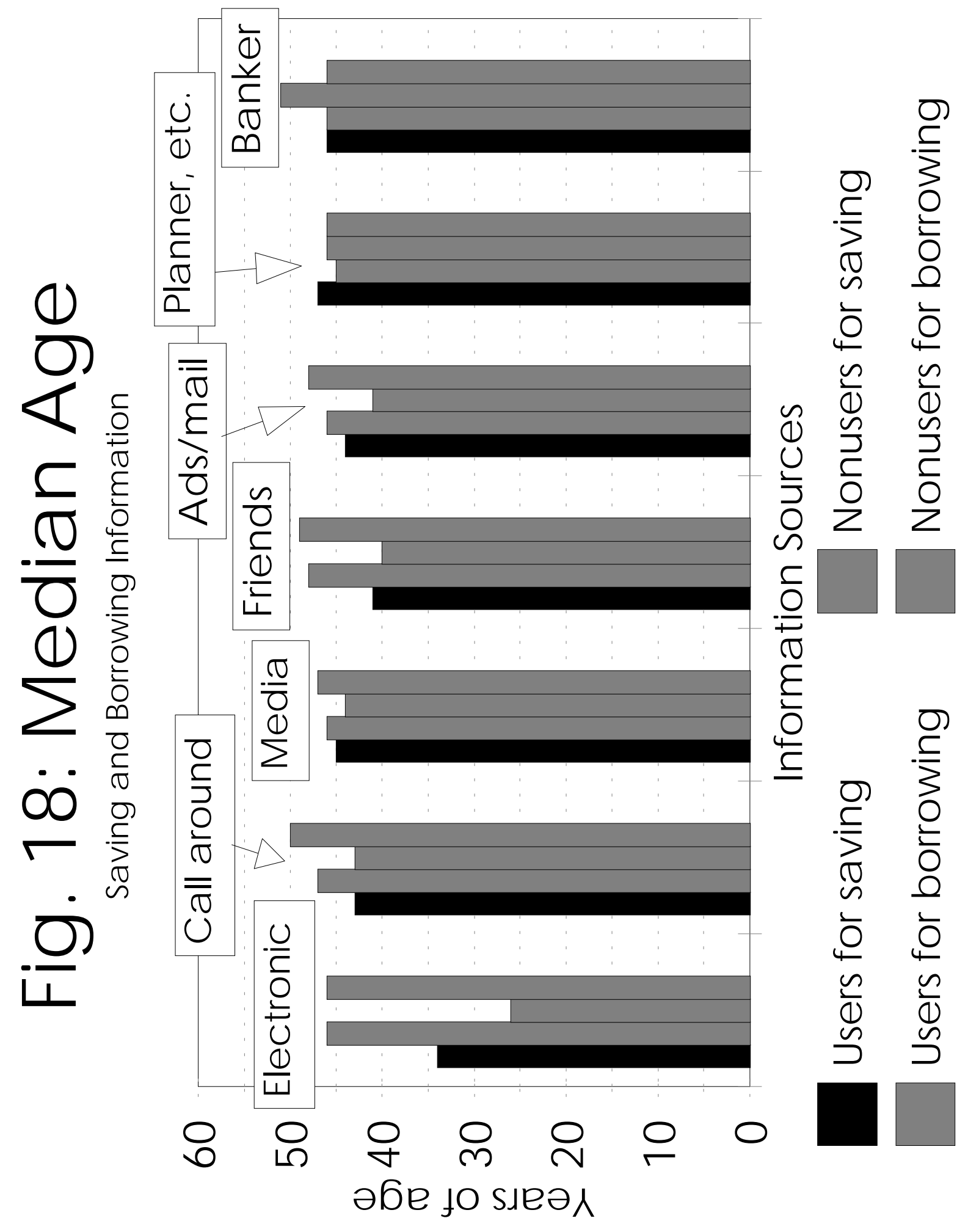




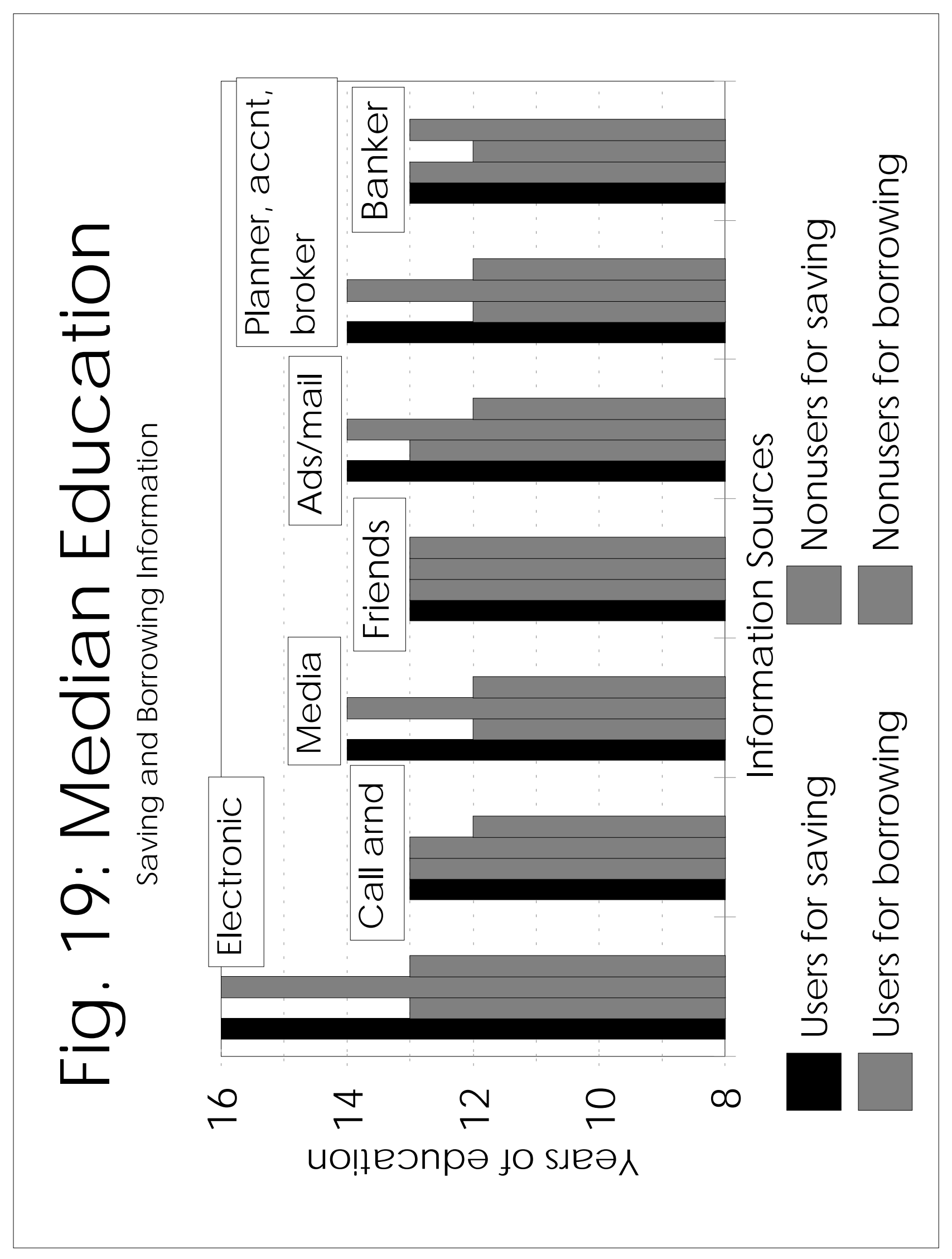

